\title{
Seismic Vulnerability Assessment for Masonry Churches: An Overview on Existing Methodologies
}

\author{
Mattia Zizi *, Jafar Rouhi (D), Corrado Chisari, Daniela Cacace and Gianfranco De Matteis \\ Department of Architecture and Industrial Design, University of Campania "Luigi Vanvitelli", \\ CE 81031 Aversa, Italy; jafar.rouhi@unicampania.it (J.R.); corrado.chisari@unicampania.it (C.C.); \\ daniela.cacace@unicampania.it (D.C.); gianfranco.dematteis@unicampania.it (G.D.M.) \\ * Correspondence: mattia.zizi@unicampania.it
}

check for updates

Citation: Zizi, M.; Rouhi, J.; Chisari, C.; Cacace, D.; De Matteis, G. Seismic Vulnerability Assessment for Masonry Churches: An Overview on Existing Methodologies. Buildings 2021, 11, 588. https://doi.org/ 10.3390 /buildings 11120588

Academic Editors: Chiara Bedon, Tomislav Kišiček, Ufuk Hancilar, Marco Francesco Funari and Mislav Stepinac

Received: 8 October 2021

Accepted: 16 November 2021

Published: 26 November 2021

Publisher's Note: MDPI stays neutral with regard to jurisdictional claims in published maps and institutional affiliations.

Copyright: (c) 2021 by the authors. Licensee MDPI, Basel, Switzerland. This article is an open access article distributed under the terms and conditions of the Creative Commons Attribution (CC BY) license (https:// creativecommons.org/licenses/by/ $4.0 /)$.

\begin{abstract}
The present manuscript deals with the seismic vulnerability assessment of existing masonry churches, which is a fundamental process for risk and consequent prioritization analyses, as well as application of effective retrofitting strategies. In the past, different approaches with various levels of accuracy and application ranges have been developed to assess the vulnerability to damage of such structures in case of seismic events. Based on the classification provided in the Italian Guidelines for the Cultural Heritage, in this paper a review of seismic vulnerability assessment methodologies for existing masonry churches is presented. The main goal of the current study is to provide a critical comparative overview about these procedures, highlighting the main issues related to the application of each detail level. Moreover, particular attention is focused on the applications present in literature, allowing for the definition of a potential systematic procedure for smart management policy aimed at preserving cultural, architectural and historical heritage.
\end{abstract}

Keywords: masonry churches; earthquakes; seismic vulnerability assessment; typological methods; macro-element approach; numerical analysis

\section{Introduction}

Nowadays, interest in the preservation of cultural built heritage, and in particular of existing masonry churches, is globally increasing [1]. Among different sources of risk threatening historical structures, seismic motion represents one of the main causes of damage and overall destruction. The mitigation of seismic risk is complex, involving hazard, exposure and vulnerability. If, on the one hand, it is not possible to manage hazard and exposure due to the intrinsic characteristics affecting sites and uses of buildings, efforts are being made by civil engineers to reduce the vulnerability of existing built heritage. Unfortunately, large areas of Europe, including Italy, are characterised by a high level of seismic hazard, and the vulnerability of ancient masonry structures is often relevant [2]. This has been widely demonstrated in survey campaigns carried out after disastrous seismic events occurred in Italy, and all over the world, during the last half century, which dramatically highlighted notable damage experienced by masonry churches. Therefore, there is a strong necessity to increase theoretical and technical knowledge aimed at improving existing methodologies for preserving valuable architectural and cultural heritage by means of risk mitigation.

The first step for seismic risk mitigation of masonry churches is represented by a seismic vulnerability assessment process, which, to date, is still difficult [3]. The complexity of studying churches and, in general, historical masonry structures mainly depends on their peculiar material characteristics and structural features, which cause significant structural deficiencies under seismic loads. In addition, it is worth noting that these heritage buildings were mainly built by skilled manufacturers based on empirical rules addressed to resist gravity loads only, and thus, in most cases, masonry churches cannot resist horizontal forces arising from seismic shaking. 
In the literature, a large number of approaches are available, corresponding to different levels of accuracy of the seismic assessment process and strongly dependent on the aim of the study and the field of application. An exhaustive classification of these methods is provided by the Italian Guidelines for the Cultural Heritage (hereinafter stated as Italian Guidelines), in which three different Evaluation Levels (EL) are distinguished [4]:

- EL1: qualitative analysis and assessment by means of simplified mechanical and statistical models.

- $\quad$ EL2: assessment of single macro-elements (local collapse mechanisms).

- EL3: global assessment of the seismic response of the structure.

In recent times, the adoption of even more simplified methods for masonry churches has been promoted. In this sense, it is possible to consider a lower level of accuracy, namely EL0, usually based on very limited typological information and adopted mainly for applications on a larger scale $[5,6]$. EL0 methods provide a risk scale rather than quantifying the seismic safety of the structures considered, which is possible with the higher-level methods. Conversely, the other Italian Guidelines' levels of accuracy allow for the determination of a seismic safety index, defined as the demand-to-capacity ratio in terms of both accelerations and return period referred to each relevant limit state. Thus, their use has been conceived at the building scale, although with different detail levels.

The first level, EL1, is based on simplified mechanical formulations, based on the estimation of a vulnerability index. In case of both churches and historical buildings, a macro-element approach is suggested within this lower-accuracy level.

The second level of accuracy, EL2, is based on the assessment of collapse mechanisms of single parts of the building, which is mostly performed by resorting to a limit analysis approach.

Finally, the third level, EL3, assesses the seismic behaviour of the entire structure by means of linear or nonlinear numerical analyses (e.g., Finite Element Method, Discrete Element Method, among others). As a consequence, it is characterised by larger accuracy than previous analyses, and a wide range of information is required for its application, including detailed geometrical, structural and mechanical characteristics of the structure.

The reliability of such methods is strictly linked to the available data and the scale of application, as well as the scope of the analyses. The scheme in Figure 1 summarizes the components of seismic vulnerability assessment related to the different levels of accuracy.

In general, both EL0 and EL1 are recognised as suitable for large-scale approaches, and thus their uses are addressed to define prioritization in the decision-making processes. On the other hand, EL2 and EL3 are considered when local or global interventions, respectively, must be realised. Nevertheless, this difference may be smoothed and, in particular, EL1 and EL2 can be profitably adopted for either territorial or building scale analyses.

In the present study, an overview of the most adopted methods for assessing the seismic vulnerability of masonry churches at a territorial scale (i.e., EL0 and EL1) and their applications is provided. More detailed methods (i.e., EL2 and EL3) are also critically discussed. The study allows for identifying the application ranges of the different methods, and finally a potential management strategy for preserving existing masonry churches is suggested. 


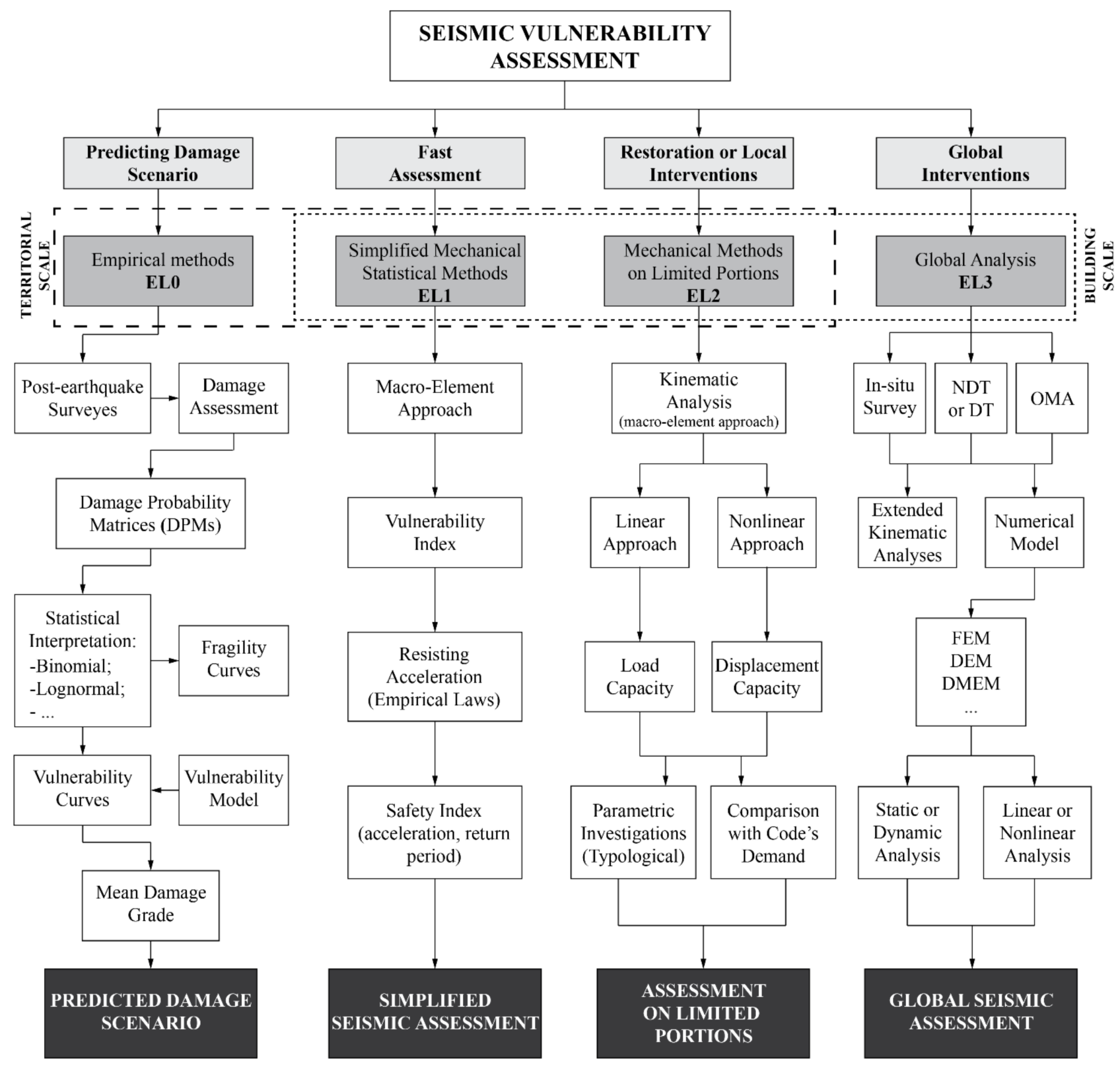

Figure 1. Components of seismic vulnerability assessment at different scales.

\section{Seismic Response of Existing Masonry Churches}

Many studies are present in the literature in which it has been noted that seismic events occurring in the last 25 years in Italy caused non-usability or access restrictions to more than $80 \%$ of investigated masonry churches in Umbria and Marche 1997 [7], Molise 2002 [8], L'Aquila 2009 [9-12], Emilia 2012 [13], Central Italy 2016-2017 [14-17], and Ischia 2017 [18]. This was confirmed after notable seismic events occurred all over the world, e.g., Perù 2007 [19], Chile 2010 [20,21], New Zealand 2010-2011 [22,23] and Mexico 2017 [24].

As noted in some of the mentioned studies, seismic vulnerability of historical masonry churches is higher than in other types of structures, including monumental buildings [2]. In particular, historical masonry churches are usually characterised by recurrent geometrical features generally favouring the occurrence of local mechanisms rather than an overall response [25], such as large wall height-to-thickness and length-to-thickness ratios, large roofing systems and openings, complex shapes and the absence of box-like behaviour, as well as insufficient connection between structural elements. 
The fact that local mechanisms are strongly favoured by such features is confirmed by post-earthquake inspections. In Figure 2, pictures of damaged churches that experienced the Central Italy earthquake of 2016-2017 are shown as examples.

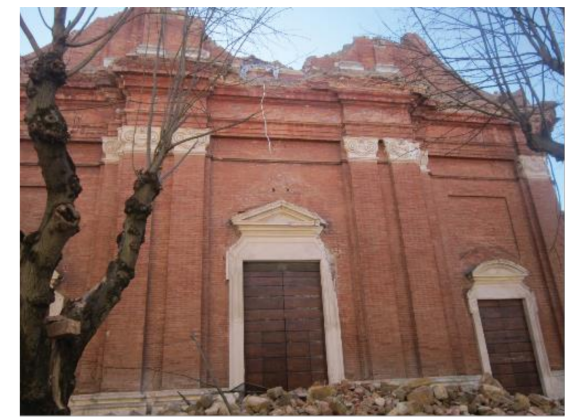

(a)

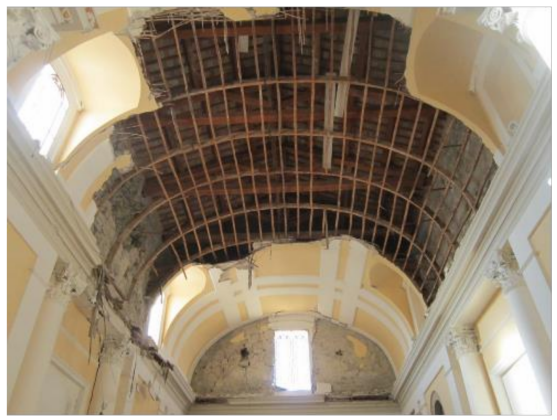

(c)

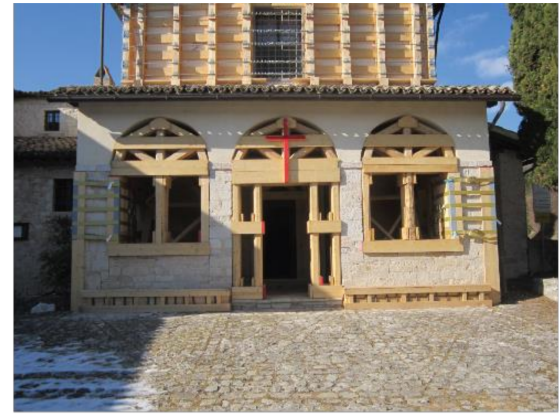

(b)

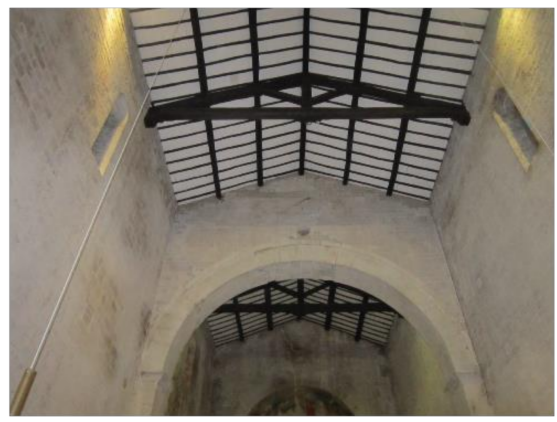

(d)

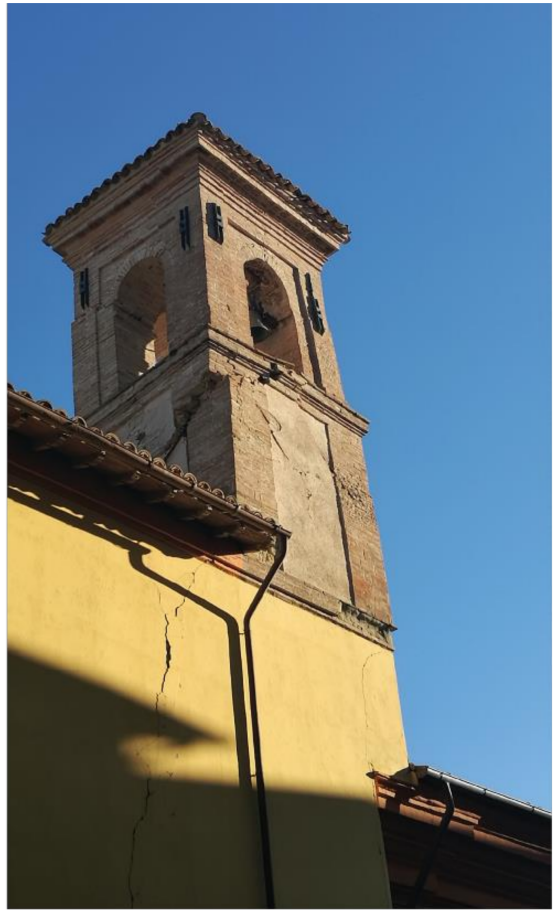

(e)

Figure 2. Examples of activation or collapse related to damage mechanisms during 2016-2017 Central Italy earthquake: (a) overturning of top façade in San Filippo church (Camerino, MC), (b) damage in the prothyrum in Santa Maria di Costantinopoli church (Cerreto di Spoleto, PG), (c) vault collapse in Santa Chiara Monastery (Camerino, MC), (d) triumphal arch damage in SS Felice and Mauro Abbey (Sant'Anatolia di Narco, PG), and (e) severe damage in the bell tower of San Carlo church (Camerino, MC).

This corroborates the approach proposed in the Italian Guidelines, where the study of masonry churches and, in particular, damage detection, is traced back to 28 possible failure mechanisms grouped in nine macro-elements. In Table 1, the identified macro-elements, and the corresponding damage mechanisms typical of Italian masonry churches, are listed.

Table 1. Damage mechanisms and macro-element of masonry churches according to Italian Guidelines.

\begin{tabular}{cl}
\hline Macro-Element & \multicolumn{1}{c}{ Damage Mechanism } \\
\hline \multirow{2}{*}{ Façade } & M1. Façade overturning \\
& M2. Overturning of the top façade \\
& M3. In-plane mechanism of façade \\
& M4. Narthex \\
& M5. Transversal response \\
Naves & M6. Shear mechanisms in the lateral walls \\
& M7. Longitudinal response \\
& M8. Central nave vaults \\
& M9. Aisles vaults \\
\hline & M10. Overturning of the transept façade \\
& M11. Shear mechanisms in the transept wall \\
& M12. Transept vaults \\
\end{tabular}


Table 1. Cont.

\begin{tabular}{cl}
\hline Macro-Element & \multicolumn{1}{c}{ Damage Mechanism } \\
\hline Triumphal arch & M13. Triumphal arch \\
\hline \multirow{2}{*}{ Dome } & M14. Dome \\
& M15. Lantern \\
\hline \multirow{2}{*}{ Apse } & M16. Apse overturning \\
& M17. Shear mechanisms in the apse \\
& M18. Apse vaults \\
\hline \multirow{2}{*}{ Roof } & M19. Mechanisms in nave roof \\
& M20. Mechanisms in transept roof \\
& M21. Mechanisms in apse roof \\
\hline \multirow{2}{*}{ Chapels and annexed bodies } & M22. Chapel overturning \\
& M23. Shear mechanisms in chapels \\
& M24. Chapel vaults \\
& M25. Plain-height irregularities \\
\hline \multirow{2}{*}{ Bell tower } & M26. Decorations \\
& M27. Bell tower \\
& M28. Belfry \\
\hline
\end{tabular}

\section{Territorial Scale Approaches: EL0 and EL1}

\subsection{Empirical and Statistical Methods: ELO}

3.1.1. From Observed Damage to Predictive Models: Fragility and Vulnerability Functions

The lowest level of the seismic vulnerability assessment, EL0, also called the macroseismic approach, is based on empirical methods aimed at predicting the expected mean damage grade, due to a seismic event of a certain intensity, on a homogeneous population of buildings having similar geometrical and constructive features. The methods belonging to this level of accuracy are calibrated based on the real damage experienced by existing buildings after an earthquake and have been particularly suitable and adopted in the recent past for masonry churches. In particular, extensive surveys allow for assigning a given church to a specific damage level $D_{k}$, which is estimated according to the EMS-98 scale ranging between $0-5$ [26] (see Table 2).

Table 2. Macroseismic Intensity Scale. Classifications used in the European Macroseismic Scale (EMS) for masonry structures (reproduced with permission from G. Grünthal [26]).

Grade 1: Negligible to slight damage (no structural
damage, slight non-structural damage) $\begin{aligned} & \text { Hair-line cracks in very few walls. } \\ & \text { Fall of small pieces of plaster only. } \\ & \text { Fall of loose stones from upper parts of buildings in } \\ & \text { very few cases. }\end{aligned}$


Table 2. Cont.

Classification of Damage to Masonry Buildings
Grade 4: Very heavy damage (heavy structural
damage, very heavy non-structural damage)
Serious failure of walls.
Partial structural failures of roofs and floors.

The global damage level $D_{k}$ is assessed as a function of a global damage index $i_{d}$ (ranging between $0-1$ ) as suggested in Table 3.

Table 3. Definition of structural damage levels for the churches, based on the damage score.

\begin{tabular}{|c|c|c|}
\hline $\mathbf{D}_{\mathrm{k}}$ & $\mathbf{i}_{\mathbf{d}}$ & Description \\
\hline 0 & $i_{d} \leq 0.05$ & No damage: light damage only in one or two mechanisms \\
\hline 1 & $0.05<i_{d} \leq 0.25$ & Negligible to slight damage: light damage in some mechanisms \\
\hline 2 & $0.25<i_{d} \leq 0.4$ & $\begin{array}{l}\text { Moderate damage: light damage in many mechanisms, with one or two mechanisms activated at } \\
\text { medium level }\end{array}$ \\
\hline 3 & $0.4<i_{d} \leq 0.6$ & $\begin{array}{l}\text { Substantial to heavy damage: many mechanisms have been activated at medium level, with } \\
\text { severe damage in some mechanisms }\end{array}$ \\
\hline 4 & $0.6<i_{d} \leq 0.8$ & $\begin{array}{l}\text { Very heavy damage: severe damage in many mechanisms, with the collapse of some } \\
\text { macroelements of the church }\end{array}$ \\
\hline 5 & $i_{d}>0.8$ & Collapse: at least $2 / 3$ of the mechanisms exhibit severe damage \\
\hline
\end{tabular}

In turn, the global damage index $i_{d}$ is calculated for each church based on the experienced damage according to Equation (1), which is proposed in the Italian Guidelines:

$$
i_{d}=\frac{1}{5} \cdot \frac{\sum_{i=0}^{28} \rho_{k, i} \cdot d_{k, i}}{\sum_{i=0}^{28} \rho_{k, i}}
$$

where: $d_{k, i}(0 \div 5)$ is the damage level observed for the $i$-th damage mechanism of Table 1 and $\rho_{k, i}(0 \div 1)$ is the corresponding score factor indicating the importance that each damage mechanism has on the global safety of the church.

The score factors $\rho_{k, i}$ were firstly defined in [8], and those values were assumed as referenced in the Italian Guidelines. Nonetheless, in some works such values are modified according to the expert judgment of the authors and thus are not fully consistent with the Guidelines' provisions (e.g., $[17,27])$, while in other works the damage mechanisms are all assumed with the same importance, with $\rho_{k, i}$ values constant and equal to 1 (e.g., $[14,15,18]$ ). In Table 4 , the values of $\rho_{k, i}$ adopted in some reference works are shown in comparison with the ranges provided by the Italian Guidelines.

The damage assessment allows for defining fragility curves, which relate the probability of damage being larger than a specified level to the intensity of the earthquake (measured with a macroseismic or peak ground acceleration scale) and are formulated based on an observational vulnerability model. One of the most adopted function for de- 
scribing the probability of damage exceedance is the binomial probability function (BDPF) shown in Equation (2).

$$
p_{k}=\frac{5 !}{k ! \cdot(5-k) !} \cdot\left(\frac{\mu_{D}}{5}\right)^{k} \cdot\left(1-\frac{\mu_{D}}{5}\right)^{(5-k)}
$$

Table 4. Values for the importance score factor $\rho_{k, i}$ assumed in reference works.

\begin{tabular}{|c|c|c|c|c|}
\hline Damage Mechanism & [8] & [4] & [17] & [27] \\
\hline M1. Façade overturning & 1 & 1 & 1 & 1 \\
\hline M2. Overturning of the top façade & 1 & 1 & 1 & 1 \\
\hline M3. In-plane mechanism of façade & 1 & 1 & 0.5 & 1 \\
\hline M4. Narthex & $0.5 \div 1$ & 0.5 & 0.25 & 0.9 \\
\hline M5. Transversal response & 1 & 1 & 1 & 0.9 \\
\hline M6. Shear mechanisms in the lateral walls & 1 & 1 & 1 & 0.9 \\
\hline M7. Longitudinal response & 1 & 1 & 1 & 1 \\
\hline M8. Central nave vaults & 1 & 1 & 0.75 & 1 \\
\hline M9. Aisles vaults & 1 & 1 & 0.75 & 0.5 \\
\hline M10. Overturning of the transept façade & $0.5 \div 1$ & $0.5 \div 1$ & 0.75 & 1 \\
\hline M11. Shear mechanisms in the transept wall & $0.5 \div 1$ & $0.5 \div 1$ & 0.5 & 1 \\
\hline M12. Transept vaults & $0.5 \div 1$ & $0.5 \div 1$ & 1 & 0.9 \\
\hline M13. Triumphal arch & 1 & 1 & 1 & 1 \\
\hline M14. Dome & 1 & 1 & 0.75 & 0.9 \\
\hline M15. Lantern & 0.5 & 0.5 & 0.25 & 1 \\
\hline M16. Apse overturning & 1 & 1 & 0.75 & 0.9 \\
\hline M17. Shear mechanisms in the apse & 1 & 1 & 0.5 & 0.9 \\
\hline M18. Apse vaults & $0.5 \div 1$ & $0.5 \div 1$ & 0.75 & 0.9 \\
\hline M19. Mechanisms in nave roof & 1 & 1 & 0.5 & 0.9 \\
\hline M20. Mechanisms in transept roof & $0.5 \div 1$ & $0.5 \div 1$ & 0.5 & 0.8 \\
\hline M21. Mechanisms in apse roof & 1 & 1 & 0.5 & 1 \\
\hline M22. Chapel overturning & $0.5 \div 1$ & $0.5 \div 1$ & 0.25 & 1 \\
\hline M23. Shear mechanisms in chapels & $0.5 \div 1$ & $0.5 \div 1$ & 0.25 & 1 \\
\hline M24. Chapel vaults & $0.5 \div 1$ & $0.5 \div 1$ & 0.5 & 1 \\
\hline M25. Plain-height irregularities & $0.5 \div 1$ & $0.5 \div 1$ & 1 & 1 \\
\hline M26. Decorations & 0.8 & $0.5 \div 1$ & 0.25 & 0.9 \\
\hline M27. Bell tower & 1 & 1 & 1 & 0.9 \\
\hline M28. Belfry & 1 & 1 & 1 & 0.9 \\
\hline
\end{tabular}

In the above equation $p_{k}$ (with $k=0 \div 5$ ) is the probability of reaching a specific damage level $D_{k}$, and $\mu_{D}$ is the observed mean damage grade in the population calculated as in Equation (3), where $n$ represents the number of considered buildings:

$$
\mu_{D}=\frac{\sum_{k=1}^{n} D_{k}}{n}
$$

The binomial distribution was firstly introduced for damage statistical analyses by Braga, Dolce and Liberatore [28], who based their study on the damage distribution matrixes (DPMs) obtained for ordinary buildings after the Irpinia earthquake (1980). By means of this methodology, the fragility curve is assumed as the cumulative probability to reach a specific damage grade, as shown in Equation (4).

$$
P\left(D \geq D_{k}\right)=\sum_{k=k}^{5} p_{k}
$$

Although, to date, the binomial distribution of the damage of Equation (2) represents the most adopted fragility function [7,8,12,29-32], it has the disadvantage of not allowing 
for an independent definition of the scatter of the expected damage, which is dependent on the only free parameter of the distribution, the mean damage $\mu_{D}$ [33]. Hence, continuous beta or lognormal distributions can be successfully adopted in order to statistically interpret the observed damage. For masonry churches, recent studies carried out after the CentralItaly 2016-2017 earthquake showed that the observed damage as a function of seismic intensity was well interpreted by a lognormal distribution.

In Equation (5) the function adopted in $[14,15]$ is shown as an example.

$$
P\left(D \geq D_{k} \mid P G A=x\right)=\phi\left(\frac{\ln (x / \mu \mid \theta)}{\beta}\right)
$$

In particular, in the above equations, $P\left(D \geq D_{k} \mid P G A=x\right)$ is the probability of exceeding a specific damage grade $D_{k}$ as function of a certain seismic intensity $P G A=x, \phi$ is the normal cumulative distribution, $\mu$ and $\theta$ are the mean and median values, respectively, (which can be alternatively adopted) and $\beta$ is the standard deviation. Hence, in these cases, the shape of lognormal fragility curves strongly depends on the parameter $\beta$, indicating the dispersion of the observed data. Thus, although unlike binomial functions they can provide several distributions of the damage, it should be noted that these formulations strongly depend on the parameter $\beta$.

Moving from an observational to a predictive approach, fragility curves can be adopted to estimate the probability of damage occurrence if the mean damage grade $\mu_{D}$ is determined a-priori. Hence, this method is suitable in combination with vulnerability curves, which can return the mean damage grade according to the seismic intensity and the vulnerability of the buildings. Some of the first authors who proposed vulnerability curves by means of a hyperbolic function were Sandi and Floricel [34]. In their study, they proposed a vulnerability function for ordinary buildings, as indicated in Equation (6):

$$
\mu_{D}=2.5 \cdot\left[1+\tanh \left(\frac{I+6.25 \cdot V_{i}-13.1}{Q}\right)\right]
$$

where the expected damage $\mu_{D}$ is evaluated as a function of the seismic intensity $I$ in macroseismic scale ( $\mathrm{I}_{\mathrm{MCS}}$ ), the vulnerability index $V_{i}$ ranges between $0-1$ according to the vulnerability classification in EMS-98 [24] and the ductility factor, $Q$, for ordinary buildings can be assumed as 2.3 .

Then, based on the damage that occurred after the 1997 Umbria and Marche seismic event, Lagomarsino and Podestà [29] calibrated vulnerability curves for existing masonry churches on the basis of a wide post-earthquake survey activity including about 2000 churches. The law proposed in this study is shown in Equation (7):

$$
\mu_{D}=2.5 \cdot\left[1+\tanh \left(\frac{I+3.4375 \cdot i_{v}-8.9125}{Q}\right)\right]
$$

In particular, the vulnerability law proposed in this study involves the use of a new vulnerability measure $i_{v}$, again ranging from 0 to 1 . Hence, in place of the vulnerability index $V_{i}$, Lagomarsino and Podestà [29] proposed adoption of a value higher than those estimated for ordinary buildings $V_{i}$, their correlation being the one indicated in Equation (8):

$$
V_{i}=0.67+0.55 \cdot i_{v}
$$

By inserting Equation (8) in Equation (6), Equation (7) is s obtained, showing the equivalence between the two formulations. In practice, Equation (7) can be considered as the result of Equation (8) introduced in Equation (6).

Moreover, in this case, $Q$ was assumed equal to 3 . It is worth mentioning that, according to Equation (7), a higher ductility factor than the one adopted for ordinary buildings (i.e., $Q=2.3$ ) means a higher mean damage grade for low-intensity (i.e., $I_{M C S}<$ VII) earthquakes, with less damage for high-intensity seismic event [32]. 
After this study, in the recent years, and with reference to different seismic events occurring in Italy and all over the world, many research activities have been carried out with the aim of verifying the reliability of these methodologies for predictive purposes by comparing the observed damage with the predicted damage $[35,36]$. While agreement on the type of vulnerability function is generally present, specific regional and typological features may be better represented by slight modifications in the coefficients. For instance, De Matteis, Brando and Corlito [32] proposed a modification to the vulnerability function provided in Equation (7) for three-nave masonry churches damaged by the L'Aquila 2009 earthquake (Equation (9)):

$$
\mu_{D}=2.5 \cdot\left[1+\tanh \left(\frac{I+6.20 \cdot i_{v}-11}{Q}\right)\right]
$$

Again, a ductility factor $Q=3$ was assumed, while the argument numerator of the hyperbolic tangent function was modified to obtain a better correspondence with the observed data.

The use of intensity measures in the vulnerability function implies a conceptual short-circuit since vulnerability depends on intensity, defined based on the effects of the ground motion on the built environment. However, those effects depend in turn on the vulnerability of the stock. In this context, De Matteis and Zizi [17] recently proposed the adoption of vulnerability functions based on a PGA-approach. In their work, the authors studied 68 one-nave churches damaged after the 2016-2017 Central Italy earthquake and highlighted good correspondence between observed and predicted damage obtained if Equation (7) is modified by means of the empirical correlation between $I_{M C S}$ and PGA proposed by Faenza and Michelini [37].

In recent years, research has moved toward the adoption of PGA-based approaches, solving the issue highlighted above and increasing the feasibility of applying this lowdetail level of accuracy (i.e., EL0) for predictive purposes. In this sense, one of the most notable examples of application is the national MaRS project promoted by the Department of Civil Protection and the consortium ReLUIS [38]. The main aim of this activity is the realization of national seismic risk maps related to several building typologies, among them churches. Although for these kinds of structures the results are still in an embryonic phase, an interesting method for deriving fragility curves from observational data has been proposed. In particular, the MaRS fragility curves are assumed with a lognormal distribution and are derived from two parameters only: (i) the median value of the PGA $A_{D 2}$ related to a damage level D2 assigned to the specific vulnerability class, and (ii) the free parameter $\alpha$ (in the range $0.36-0.66$ indicating the brittle or ductile behaviour, respectively) for determining the PGA values related to the damage level $D_{k}$ according to Equation (10).

$$
P G A_{D k}=P G A_{D 2} \cdot e^{\alpha(k-2)} k=1, \ldots, 5
$$

Also in this case, the fragility curves assigned to a specific building typology strongly depend on the dispersion $\beta$ assumed for the lognormal distribution.

Nonetheless, to date, the vulnerability function of Equation (7) still appears the most adopted and robust law for fitting the observed damage, and thus could be adopted for predictive purposes, too. A graphical representation of the vulnerability curves obtained by applying Equation (7), and the consequent generic fragility curves (with a binomial distribution, see Equation (4)), are provided in Figures 3 and 4, respectively.

\subsubsection{Vulnerability Assessment: EL0 Methods and Applications}

In the past decades, the application of vulnerability and fragility curves has seen wide application not limited to masonry churches. Nowadays, the research world is still moving to corroborate such empirical formulations to adopt them for predictive (and thus preventive) aims within a territorial approach. 
It is clear, now, that one of the most complex issues in this field is the definition of a vulnerability parameter, which should be based on few typological characteristics to allow a fast large-scale assessment. In the following, some relevant literature works, not limited to the Italian context and addressing this issue, are reported. It must be pointed out that these methodologies have been adopted in combination with various vulnerability and/or fragility functions. Thus, it must be admitted that the different vulnerability models suggested in each work only make sense within the scope of the specific framework to which they refer.

Generally, within the low-detail level EL0, the vulnerability parameter is estimated according to an initial value $\left(V_{0}\right)$, which is modified accounting for typological and geometrical characteristics as indicated in Equation (11), where the choice of the modifying parameters $\left(V_{k}\right)$ and relative scores are empirically determined on the basis of statistical analyses and expert judgements $[1,30]$.

$$
V_{i}=V_{0}+\sum V_{k}
$$

In the literature, many examples of similar EL0 vulnerability models are present, which are based on Equation (11) or its modifications. A notable example of this method has been implemented within the European Risk-UE project [39], which involved seven European cities (Barcelona, Bitola, Bucharest, Catania, Nice, Sofia and Thessaloniki). Therein, a vulnerability model suitable for several ancient masonry construction typologies is provided and, in particular, $V_{0}=0.89$ is defined for churches. The value is then modified according to Equation (11) and by accounting for seven parameters: (i) state of maintenance, (ii) quality of materials, (iii) regularity in plan, (iv) regularity in elevation, (v) position in the urban context, (vi) retrofitting interventions, and (vii) site morphology. As shown in Table 5, these modifiers may have an increasing or decreasing effect on the vulnerability, based on the quality of the feature. Examples of application of this methodology can be found, among others, in $[1,30,40]$.

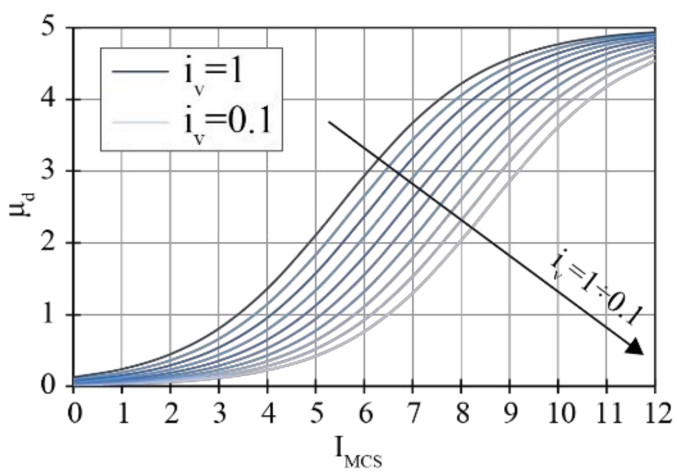

(a)

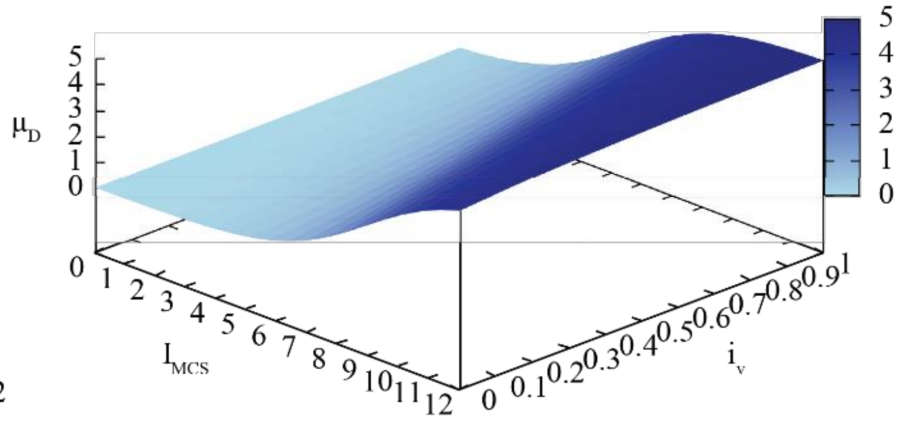

(b)

Figure 3. Vulnerability function in (a) $I_{M C S}-\mu_{D}$ plane and (b) $I_{M C S}-\mu_{D}-i_{V}$ space.

It is worth specifying that the main aim of the European Risk-UE project was to provide unified vulnerability functions regardless of the investigated structural typologies (e.g., towers, bridge, churches) and with this method a vulnerability score in the range 0.63-1.22 can be obtained, which is consistent with Equation (8). 


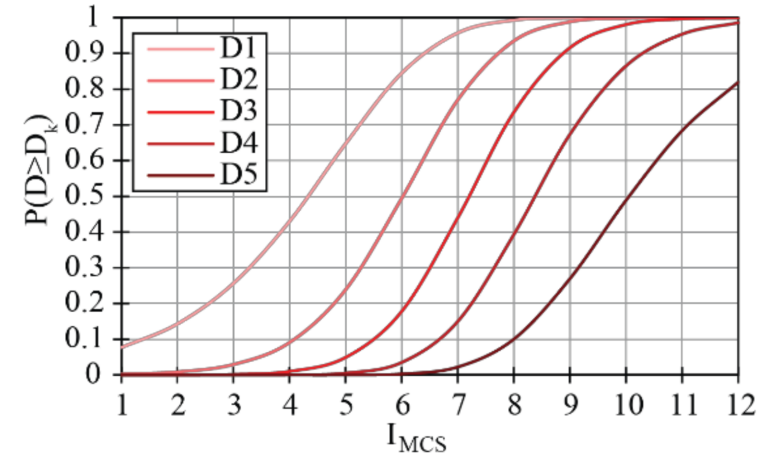

(a)

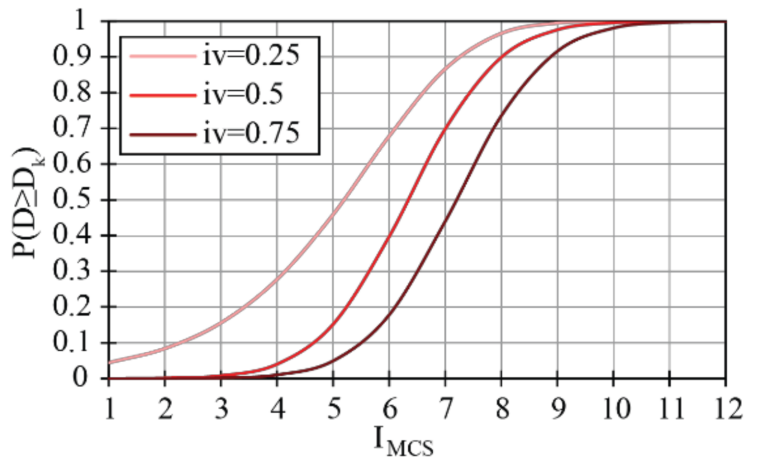

(b)

Figure 4. Fragility function: (a) curves for $i_{v}=0.5$, and (b) curves related to $D_{k}=3$ for different levels of vulnerability.

Table 5. Reference values of modifiers scores $\left(V_{k}\right)$ (adapted from [4]).

\begin{tabular}{|c|c|c|c|}
\hline Parameter & & $V_{k}$ & \\
\hline State of Maintenance & very bad $=0.08$ & Medium $=0$ & $\operatorname{good}=-0.04$ \\
\hline Quality of Materials & $\mathrm{bad}=0.04$ & medium $=0$ & $\operatorname{good}=-0.04$ \\
\hline Planimetric Regularity & irregular $=0.04$ & regular $=0$ & symmetrical $=-0.04$ \\
\hline Regularity in elevation & irregular $=0.02$ & & regular $=-0.02$ \\
\hline Interactions (aggregate) & corner position $=0.04$ & isolated $=0$ & included $=-0.04$ \\
\hline $\begin{array}{l}\text { Retrofitting } \\
\text { Interventions }\end{array}$ & & effective interventions $=-0.08$ & \\
\hline Site Morphology & ridge $=0.08$ & slope $=0.04$ & flat $=0$ \\
\hline
\end{tabular}

A similar approach is proposed in [27]. In this work the authors proposed a simplified seismic risk model assessed by means of hazard and vulnerability scores. Vulnerability is estimated by examining thirteen parameters, ten of which are derived from the Italian GNDT II vulnerability datasheet [41]. In this case, the vulnerability model assumes the form of Equation (12):

$$
V_{i}=\sum_{k=1}^{13} \rho_{k} \cdot v_{k, i}
$$

where $v_{k, i}$ is the score value $i$ of the class selected for the generic $k$-th parameter, while $\rho_{k}$ is the weight, representing the importance that each parameter has on the global vulnerability of the church.

Geometrical-based simplified methods, which consider geometrical features to obtain approximate vulnerability indexes, are worth mentioning, too. For example, Lourenço and Roque [42] proposed three simplified safety indexes based on a study concerning 58 Portuguese churches: (i) in-plan area ratio, (ii) area-to-weight ratio, and (iii) base shear ratio. In this work, a vulnerability score is suggested as an indicator for fast screening aimed at prioritizing deeper assessment studies. Similarly, in the work of Salzano et al. [18], vulnerability classes for 27 churches damaged after the Ischia earthquake (2017) are defined according to a fictitious slenderness parameter, namely nave height to square root of the plan area ratio. In this case, the authors examined a wide set of vulnerability functions in order to obtain the best correlation with the observed data.

Another significant study carried out by Palazzi et al. [43] deals with 106 masonry churches that experienced the 2010 Maule earthquake (Central Chile). In this work, the authors tried to find a correlation between the experienced seismic intensity and damage level, and four typological parameters, i.e., (i) masonry type, (ii) architectural layout, (iii) architectural style, and (iv) foot-print area. 


\subsection{Simplified Mechanical, Statistical and Qualitative Models: EL1}

\subsubsection{Safety Assessment}

Whereas with the previous level of accuracy it is possible to estimate an expected damage, or the probability of attaining a certain damage grade on a homogeneous population of buildings, with the EL1 approach a simplified safety check can be carried out. In particular, this approach is aimed at estimating a safety index $I_{S}$ to define a suitable risk classification and possibly highlight the need for further studies and planning interventions for the mitigation of seismic risk. Hence, its application is mainly referred to the regional diocesan and municipal scale, since for its application an accurate inspection by expert practitioners is required.

The method is widely described in the Italian Guidelines, and it is based on empirical rules calibrated on the data observed in the aftermath of Marche 1997 and Molise 2002 earthquakes $[5,6,27]$. A brief outline is provided below.

The safety index $I_{S, L S}$ can be estimated, for each limit state $L S$, according to Equation (13), where $T_{R, L S}$ is the prescribed return period of the seismic action (demand), and $T_{L S}$ is the actual return period of the seismic action for which $L S$ is attained (capacity):

$$
I_{S, L S}=\frac{T_{L S}}{T_{R, L S}}
$$

The Italian Guidelines require masonry churches to consider three limit states:

- The Life Safety Limit State (LSLS), which is considered attained when the building, after a seismic event, experiences collapse of nonstructural elements and relevant damage of the structural components, thus provoking a significant loss of global stiffness with respect to horizontal actions.

- The Damage Limit State (DLS), which is considered attained when the building, after a seismic event, experiences a global damage level (including both structural and non-structural elements) so that the safety of people and the capacity of the structure in bearing vertical and horizontal loads are not endangered.

- The Damage Limit State for Artistic Assets (ALS), which is considered attained when the artistic assets (such as such as frescoes, wall paintings, stone carving, etc.) in the building suffer low damage so that they can be restored without a significant loss of their cultural value.

To define the demand in LSLS and DLS conditions, and thus the corresponding return periods $T_{R, S L}$, the exceedance probability of the seismic action $P_{V R}=10 \%$ and $P_{V R}=63 \%$, respectively, are considered. On the other hand, for assessing the ALS attainment, a $P_{V R}=63 \%$ is, again, considered, while the nominal life is reduced according to a $\eta$ factor, accounting for the number of checks usually carried out on the specific artistic asset. Since the main aim of this methodology is to perform a fast assessment for prioritization processes on a territorial scale, the same nominal life for the considered churches (e.g., $V_{N}=50$ years) is suggested.

In addition, seismic safety in terms of the acceleration factor is also provided by the Italian Guidelines (namely $f_{a, L S}$ ), which is defined as the ratio between the demand peak ground acceleration (PGA) for the limit state $\left(a_{L S}\right)$ and the corresponding capacity $\left(a_{g, L S}\right)$, as indicated in Equation (14).

$$
f_{a, L S}=\frac{a_{L S}}{a_{g, L S}}
$$

Within the application of the EL1 method for assessing the seismic safety of a masonry church, the LSLS and DLS are considered. A direct correlation between $a_{L S}$ and the vulnerability score $i_{v}$ ranging between $0-1$, is proposed. The empirical formulations 
provided by the Italian Guidelines for masonry churches and the two considered limit states are provided in Equation (15):

$$
\begin{aligned}
& a_{D L S} \cdot S[g]=0.025 \cdot 1.8^{2.75-3.44 \cdot i_{v}} \\
& a_{L S L S} \cdot S[g]=0.025 \cdot 1.8^{5.1-3.44 \cdot v_{v}}
\end{aligned}
$$

In the above equations, $S$ is the coefficient accounting for the subsoil category and the topographic conditions defined according to the Italian Technical Code.

Hence, in order to estimate the safety index $I_{S}$ (Equation (13)), it is necessary to evaluate the return period corresponding to the attainment of the considered limit state by interpolating between two known values related to predefined return periods, peak accelerations on rigid soil and soil condition as in Equation (16).

$$
T_{L S}=T_{R 1} \cdot 10^{\log \left(T_{R 2} / T_{R 1}\right) \cdot \log \left(a_{L S} S / F_{C} a_{1} S_{1}\right) / \log \left(a_{2} S_{2} / a_{1} S_{1}\right)}
$$

In Equation (16), $T_{R 1}$ and $T_{R 2}$ are the return periods for which the seismic hazard is provided and that define the range including $T_{S L}, a_{1}$ and $a_{2}$ are the corresponding peak ground acceleration on rigid soil and $F_{C}$ is the confidence factor, which for such analyses can be assumed $F_{C}=1.35$, while $S_{1}$ and $S_{2}$ are the soil coefficients, as mentioned above.

The exponential trends obtainable by applying Equations (15) and (16) are shown in Figure 5. In the figure, a flat rigid soil has been considered. Moreover, a generic site has been selected and the return periods related to the different limit states have been normalized with respect to the maximum value referred to the DLS (Figure 5b).

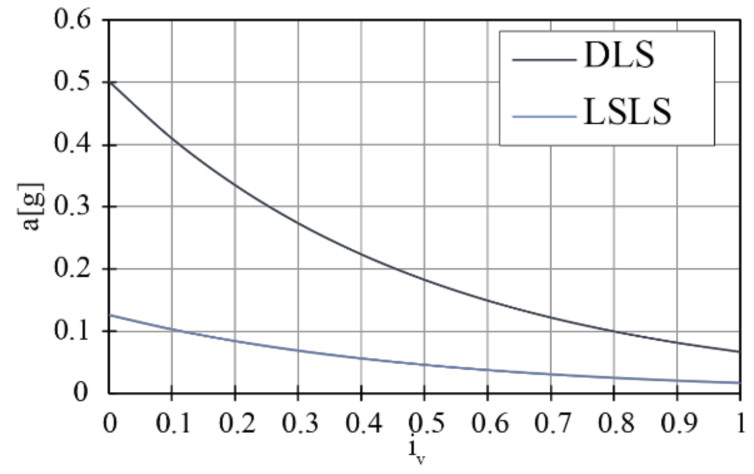

(a)

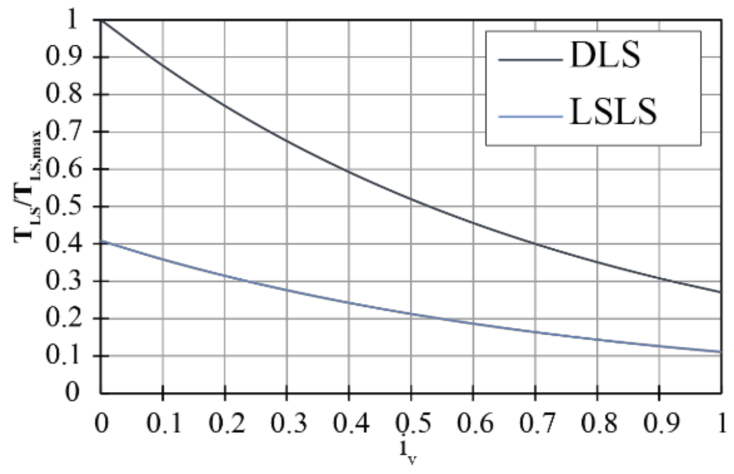

(b)

Figure 5. EL1 methodology according to Italian Guidelines related to DLA and LSLS: (a) acceleration capacity versus vulnerability index and $(\mathbf{b})$ return periods versus vulnerability index.

\subsubsection{Vulnerability Assessment: EL1 Methods and Applications}

It is evident that, similar to EL0, a parameter describing the vulnerability of the considered structure plays a fundamental role in the EL1 approach. In this case, the Italian Guidelines provide an empirical formulation based on the so-called macro-element approach. In particular, the vulnerability index is evaluated as a weighted average of the scores related to the potential damage mechanisms of Table 1, accounting for the presence of fragility indicators and anti-seismic devices:

$$
i_{v}=\frac{1}{6} \cdot \frac{\sum_{k=1}^{28} \rho_{k} \cdot\left(v_{k, i}-v_{k, p}\right)}{\sum_{k=1}^{28} \rho_{k}}+\frac{1}{2}
$$

Here, $\rho_{k}$ is the same importance score factor adopted in the damage assessment (see Table 2) and assigned to each mechanism according to the influence that it has on the 
global behaviour of the structure (i.e., $\rho_{k}=0$ if the mechanism cannot occur), while $v_{k, i}$ and $v_{k, p}$ are the scores related to both the presence (and the severity) of fragility indicators, and the presence (and the efficiency) of antiseismic devices related to the $k$-th mechanism, respectively. $v_{k, i}$ and $v_{k, p}$ can be estimated according to the number of elements influencing the seismic vulnerability of the damage mechanism and the expert judgment on their effectiveness (ranging between 1-3), as shown in Table 6.

The formulation for assessing the vulnerability index according to the EL1 procedure is only partly consistent with that adopted for EL0. Indeed, starting from a base value (i.e., 0.89 for EL0, 0.5 for EL1), the index is modified according to fragility indicators and the presence of antiseismic devices, in EL1 based on a more accurate survey of the potential damage mechanisms of the macro-elements. In past works, it has been shown that the application of this method to Italian churches generally returns vulnerability indices close to the median 0.5. In this context, among others, the following contributions are worth mentioning: the study of De Matteis, Brando and Corlito [32], which deals with churches that experienced the L'Aquila earthquake, the work of De Matteis and Zizi [17] that focuses on one-nave churches of Central Italy, the analyses performed by Salzano et al. [18] on churches damaged after the Ischia seismic event of 2017, and the study of D'Amato, Laterza and Diaz Fuentes [27] on Matera's churches. In addition, by applying Equation (17) it can be noted that under the assumptions of rigid and flat soil, the resisting ground acceleration in SLSL conditions passing from $i_{v}=0.6$ to $i_{v}=0.4$ is almost doubled. This indeed means that a small variation of the vulnerability index could lead to significant differences in expected strength.

Table 6. Evaluation of the vulnerability modifiers (adapted from [4]).

\begin{tabular}{ccc}
\hline $\begin{array}{c}\text { Number of Vulnerability Indicators or } \\
\text { Antiseismic Devices }\end{array}$ & Judgment of Effectiveness & $\boldsymbol{v}_{\boldsymbol{k}}$ \\
\hline At least 1 & 3 & 3 \\
At least 2 & 2 & 3 \\
1 & 2 & 2 \\
At least 2 & 1 & 2 \\
1 & 1 & 1 \\
None & 0 & 0 \\
\hline
\end{tabular}

Overall, since the EL1 vulnerability assessment foresees accurate surveys of masonry churches, it can be considered mainly suitable for territorial applications with a lower scale than EL0, such as a provincial or regional scale. Examples of application of this method can be found, among others, in $[18,27]$.

\section{Building Scale Approaches: EL2 and EL3}

\subsection{Assessment Based on Limit Analysis Concept: EL2}

\subsubsection{Field of Applications and Fundamentals of Limit Analysis}

Whereas previous levels of accuracy (ELO and EL1) are mainly adopted in large-scale applications, an EL2 method is, in principle, suitable for structural-scale applications. EL2 methods are based on the limit analysis by adopting static and kinematic approaches. Hence, the mechanical characteristics of the masonry are disregarded with such approaches, and Heyman's assumptions of the masonry behaviour can be adopted: (i) infinite compressive strength, (ii) zero tensile strength, and (iii) absence of sliding failures [44]. These simplified hypotheses can be assumed within the static and kinematic theorems, which respectively explore statically balanced and kinematically compatible solutions.

Static approaches consist of graphical methods based on the theories developed in France during the 18th and 19th centuries concerning the structural safety of masonry arches founded on the line-of-thrust concept $[45,46]$. These methods try to find the unique kinematically compatible solution among those admissible that are in equilibrium with external loads. On the other hand, limit analyses with a kinematic approach are widely 
utilized to study any portion of the entire building that can exhibit recognizable failure mechanisms. This holds true not only for masonry churches, since such an approach is considered by technical codes also for generic masonry structures. The kinematic approach tries to find the unique balanced solution among those corresponding to kinematically compatible mechanisms.

When a linear approach is assumed, the method allows determination of the multiplier of a load distribution by simulating the seismic action for which a failure mechanism is activated in the considered structural element, and thus can be used for a check in Damage Limit State (DLS) conditions. On the contrary, the attainment of the Life Safety Limit State (LSLS) can be verified with a simplified methodology (linear approach with behaviour factor) or by resorting to nonlinear kinematic analysis, which involves the evaluation of the load multiplier at different levels of mechanism amplitude.

\subsubsection{Limit Analysis by Means of Kinematic Approach}

Kinematic limit analysis consists of subdividing the investigated structural component in a set of rigid blocks linked to one another by means of a minimum number of nondissipative hinges creating a mechanism (i.e., kinematic chain). Hence, by adopting the principle of virtual works, it is possible to identify the multiplier of a load distribution which brings the system into equilibrium. The mechanism corresponding to the minimum multiplier is identified as the collapse multiplier. Since infinite hinges distributions can be considered, the analysis can be performed by following two approaches: (i) by conveniently minimising the load multiplier by means of automatic procedures, or (ii) by a-priori defining a block subdivision for a predetermined failure mechanism, which is recurrent or compatible with real crack pattern already present in the considered element.

The load multiplier $\left(a_{0}\right)$ for which the activation of a failure mechanism is achieved can be estimated according to Equation (18):

$$
a_{0}=\frac{\sum_{k=1}^{N} P_{k} \cdot \delta_{P y, k}-\sum_{k=1}^{m} F_{k} \cdot \delta_{F, k}+L_{i}}{\sum_{k=1}^{N}\left(P_{k}+Q_{k}\right) \cdot \delta_{P Q x, k}}
$$

where $N$ is the number of blocks constituting the kinematic chain, $m$ is the number of external loads applied on each block, $P_{k}$ is the resultant weight-force vector applied on the $k$-th block; $Q_{k}$ is the resultant weight-force vector not loading the $k$-th block but whose mass provokes an horizontal seismic action on it, $F_{k}$ is the external load applied on the $k$-th block, $\delta_{P y, k}$ is the vertical virtual displacement of the $k$-th block centroid, $\delta_{F, k}$ is the virtual displacement dual to $F_{k}$ at its application point, $\delta_{P Q x, k}$ is the horizontal virtual displacement of the centroid of forces $P_{k}$ and $Q_{k}$ applied on the $k$-th block, and $L_{i}$ is the work produced by internal forces.

The so-defined load multiplier has to be converted in spectral terms $\left(a_{0}{ }^{*}\right)$ by means of Equation (19):

$$
a_{0}^{*}=\frac{a_{0} \cdot g}{F C \cdot e^{*}}
$$

Here, $g$ is the gravity acceleration, $F C$ is the confidence factor ranging between 1-1.35 according to the level of knowledge $(\mathrm{KL})$ of the structure, and $e^{*}$ is the mass participating in the considered mechanism, which is estimated as indicated in Equation (20).

$$
e^{*}=\frac{\left[\sum_{k=1}^{N}\left(P_{k}+Q_{k}\right) \cdot \delta_{P Q x, k}\right]^{2}}{\left[\sum_{k=1}^{N}\left(P_{k}+Q_{k}\right)\right] \cdot\left[\sum_{k=1}^{N}\left(P_{k}+Q_{k}\right) \cdot \delta_{P Q x, k}^{2}\right]}
$$

Hence, safety checks with respect to DLS and LSLS can be carried out by comparing the demand in terms of spectral acceleration and the capacity $a_{0}{ }^{*}$, which in the second 
case can be increased by means of the behaviour factor $q$ (usually adopted equal to 2 for these analyses).

On the contrary, if a nonlinear approach is adopted, the evolution of the mechanism, described by the displacement of a control point, is followed until the load multiplier becomes zero. In this case, the failure mechanism is described by means of a capacity curve (acceleration versus displacement) assumed as a single degree of freedom system (SDOF). Such an approach allows the estimation of the post-peak response, thus not being particularly suitable for assessing the seismic vulnerability of masonry churches, for which the Collapse Limit State (CLS) is usually not considered.

Many examples of EL2 applications can be found in the literature. In particular, they are referred to several damage mechanisms of entire churches $[21,27,47]$ or single macro-elements [48-50]. Whereas in the first cases the approach can lead to designing local retrofitting interventions, the second approach entails performing parametric studies on macro-elements, e.g., arches and vaults characterised by typical dimensional features. If extended to the complete set of vulnerable macro-elements, this has the potential to become the basis for systematic fast assessment tools based on sole geometrical features.

\subsection{Detail Global Seismic Assessment: EL3}

\subsubsection{General}

The most accurate level for assessing the seismic vulnerability of existing masonry churches and historical masonry buildings, is based on the analysis of detailed numerical models. At the scale of the single structure, the Italian Guidelines also suggest the adoption of simplified methods (EL2) applied to each element of the construction. Nevertheless, studying the entire building by means of its numerical representation allows the practitioner to design a global retrofitting intervention rather than localized measures aimed at improving the seismic response of single macro-elements.

\subsubsection{Numerical Models and Fields of Application}

Numerical modelling of the seismic response assessment of complex masonry structures, such as churches, which are often characterized by inhomogeneous materials with poor connections between orthogonal walls, is not an easy task. The approaches most generally used fall in two main categories: Finite Element Methods (FEM) and Discrete Element Methods (DEM).

Among FEM, differences are related to:

- the representation of masonry, i.e., detailed or simplified micromodelling and macromodelling [51].

- the geometrical discretisation, i.e., monodimensional [52,53], two-dimensional $[54,55]$ and three-dimensional elements [56,57].

- the material models, i.e., discrete or smeared approaches [58] in combination with plastic, damage or plastic-damage materials [59].

With reference to masonry representation, it can be certainly asserted that the macromodelling approach is the most adopted one for masonry churches [60-64]. With such an approach, units and joints are not individually modelled, but the material is represented as an equivalent homogeneous continuum, and thus computational efficiency is attained at the expenses of some simplifications. For instance, macro-models are not perfectly able to reproduce sliding failures and out-of-plane mechanisms, which, conversely, can be well interpreted with more detailed modelling approaches. Nonetheless, the latter issue can be profitably solved by introducing contact-like constraints between walls rather than guarantying a perfect node congruence of the mesh [51,65]. More detailed approaches (meso and micro-modelling, in which the masonry bond is entirely represented) entail more significant modelling and computational efforts, which can be not particularly suitable when the seismic responses of entire buildings are assessed and thus, they can be profitably adopted for single portions (e.g., vaults, walls, arches, etc.) $[66,67]$. 
As regards the geometrical discretisation, it must be pointed out that some of the simplified hypotheses usually assumed for ordinary buildings are not fully appropriate in case of masonry churches, given the absence of stiff a horizontal diaphragm and the significant slenderness of the structures favouring out-of-plane mechanisms. Hence, the Equivalent Frame Method (EFM), which is the analysis method generally suggested by Eurocode 6 for masonry structures, cannot be considered suitable, and the choice should fall on models having two-dimensional or three-dimensional elements [68]. When masonry elements are characterized by significant thicknesses, which is typical of ancient masonry churches, three-dimensional elements are preferred since flexural, shear and rocking failures can be better interpreted.

As far as material modelling is concerned, generally models developed for simulating the behaviour of concrete and other quasi-brittle material with low tensile strength can be adopted in FE simulations. The choice can fall among material models entailing discrete or smeared approaches, which simulate the cracking process by introducing mesh discontinuities or by nonlinear behaviour of the homogenised material, respectively [58]. In both cases, one of the most notable issue is the definition of the tensile behaviour, which greatly affects the analysis in terms of both global seismic response and stability (convergence problems) [69]. As for all materials showing softening, mesh dependency can be reduced or avoided by using a variety of approaches including nonlocal approaches [70], higher-order continuum models [71], as well as regularization processes [72]. Overall, the latter formulations, which are based on the concept of fracture energy, are preferred since they are relatively easy to implement and little sensitive to mesh, which in case of complex geometries is usually very variable.

With DE models the structure is modelled as an assemblage of distinct blocks (rigid or deformable) interacting with one another according to contact constitutive laws, which, in turn, account for possible failure mechanisms. Such a method, which was first introduced for geotechnical problems by Cundall and Strack [73], has formerly found wide application in civil engineering problems, especially related to granular materials such as masonry [74-76]. Several aspects distinguish different DE models. Among others, should be mentioned: (i) block representation; (ii) contact laws; (iii) solution methods, and (iv) material properties [77]. As mentioned above, the block in DEMs can consist of rigid or deformable elements. In the first case, the deformation is totally accounted for in joints, while in the second case a finite element mesh should be introduced. The interaction between blocks, can be, in turn, schematized by single-point or multi-point contacts characterized by normal and tangential stiffness and strength parameters. In general, the higher the complexity of the interaction, the more accurate results are expected, and the more computational efforts are required. As far as solution methods are concerned, explicit solutions are generally preferred to implicit ones since, with such models, large displacements are almost always expected.

Generally, one of the most notable issues in adopting DEMs for simulating the seismic response of complex structures, such as masonry churches, is the requirement of a significant modelling effort. Nonetheless, recent studies have demonstrated that by adopting block sizes larger than the actual masonry units, acceptable results can be obtained until the discretization is representative enough [78,79]. The recent Discrete Macro-Element Method is an extension of DEM proposed by researchers at the University of Catania [80] to increase computational efficiency. With this strategy, the discrete elements, originally referring to the masonry units, are extended to represent entire masonry components (walls and spandrels) having shear deformability and mechanically interacting with the adjacent elements by means of zero-thickness cohesive interfaces. The strong reduction of degrees of freedom compared to equivalent FEM and the adoption of suitable uniaxial cyclic models allow for computational efficiency and remarkable accuracy.

As far as the fields of application are concerned, the detailed level of accuracy EL3 is mainly referred to single churches [60-65], although in some studies it is extended to more church types in order to identify the typological features most influencing the structural 
response. A notable example in this sense is the work performed by Valente and Milani [3], who studied the seismic responses of seven masonry churches in Ferrara. A similar approach was followed in [81] but with reference to a regional context (Abruzzi region).

\subsubsection{Types of Analysis and Typical Issues}

Apart from the modelling features outlined above, EL3 assessment can be based on linear or nonlinear analysis and different load types (static or dynamic). Examples of different approaches can be found, among other, in [63,64,82-84]

The most common strategies in this field are static nonlinear analyses (i.e., pushoveranalyses). With pushover analyses, structures are subjected to increasing horizontal loads until failure, considering both a mass-proportional and modal-proportional distribution. One of the most critical aspect in such kinds of analysis is the definition of the ultimate displacement, which is assumed when the base shear-control displacement plot exhibits a strength degradation up to $15-20 \%$ of the maximum force. However, since the response is mainly governed by out-of-plane and local failures, this definition of collapse is often very difficult to obtain. This holds even truer if simplified post-linear behaviour is assumed, as in the elastic-perfectly plastic material models allowed by the Italian Guidelines. Hence, standard procedures for ordinary buildings consisting of comparing demand and capacity displacements could be difficult to apply. A critical, and not always straightforward, interpretation of the results is thus always required.

\section{Critical Discussion and Proposal of a Smart Management Policy}

\subsection{Inclusion of Strengthening Solutions}

The seismic risk mitigation of existing masonry churches is based on an accurate process of vulnerability assessment that, as discussed above, can be performed at different detail levels. On the other hand, vulnerability can be definitively reduced by realizing strengthening interventions, which may be designed by resorting to the most detailed evaluation levels only (i.e., EL2 and EL3). To preserve the architectural, cultural and historical values of existing masonry churches, the choice should fall on interventions guaranteeing the principles of low invasiveness, reversibility and compatibility with existing surfaces.

Each of the analysed levels can, however, account for the effects of strengthening interventions for the vulnerability assessment. In the case of EL0 they can strongly modify the vulnerability parameter, as it can be noted for example in Table 5, where the score related to the presence of effective interventions has the lowest (and thus most influencing) value (i.e., -0.8$)$.

With reference to the Guidelines' method EL1, the presence of antiseismic devices should be accounted for according to their effectiveness, which should be estimated based on expert judgment (see Table 6). An example of efficiency of anti-seismic devices can be made by considering tie rods, whose effectiveness can be estimated according to the anchor plates typology. In particular, it can be assumed that the larger the masonry-plate contact surface, the higher is the effectiveness of the tie rods. Examples of differently effective tie rods are provided in Figure 6.

On the contrary, with EL2 and EL3 the effects of strengthening interventions can be assessed in a closed form, evaluating the improvements in terms of both strength and ductility. Valuable examples of studies aimed at estimating the effects of retrofitting interventions based on limit analysis (EL2) are proposed, among others, in [85] for towers and in [86] for buttressed arches.

With reference to EL3 methodologies, many examples [87-89], just to mention a few, are present in the literature where masonry churches are studied both in ante and post-operam conditions, since this is the most natural and unique way to design global interventions (see Figure 1). 


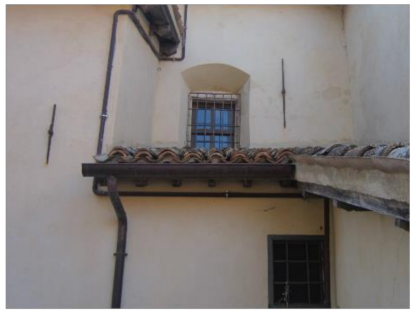

(a)

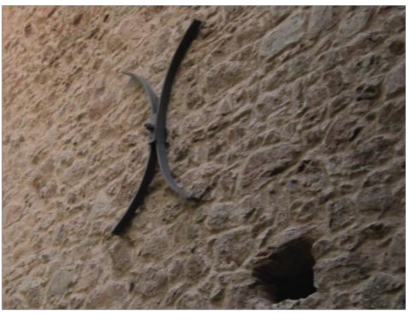

(b)

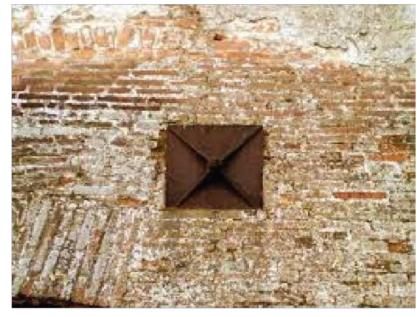

(c)

Figure 6. Different anchorages of tie rods for masonry buildings: low (a), medium (b) and high (c) efficiency.

\subsection{Pros and Cons of Different Detail Levels}

As regards empirical and statistical methods, it can be stated that reliable EL0 models are more suitable than EL1 models for territorial-assessment approaches, given that vulnerability models for estimating a damage scenario by means of vulnerability and fragility functions are based on few typological parameters, and their application does not require accurate in-situ inspections and expert judgment.

In this sense, it should be highlighted that only recently the research community has been definitively moving toward a PGA-based approach, which can be adopted for predictive purposes. These methods require an accurate calibration based on more precise models or statistical interpretation of the observed damage, and they have shown high reliability when homogeneous populations of buildings are investigated. In this sense, it is evident that, together with appropriate exposure and hazard models, they represent a strong tool for management policies since they can provide a sort of priority scale returning the riskiest population of churches. Nonetheless, inconsistencies have been observed among the different proposals of vulnerability and fragility curves present in the literature. This can be related to several factors, such as the several regional, provincial or diocesan contexts analysed, the subjectivity of the users called to assign both damage and vulnerability levels to each considered church, and the absence of a unified and robust methodology for interpreting damage distribution (e.g., binomial, lognormal, beta continuous, etc.).

Hence, the accuracy of the several formulations analysed in this overview are strongly dependent on the cases used for their calibration. A possible solution to this problem could entail PGA-based laws for predicting the damage scenario, which differ to one another in function of the considered context (e.g., regional or diocesan), although this approach suffers from a generalised lack of data. On the whole, the debate concerning the definition of the most reliable model is still open, since it is the authors' opinion that, in the light of above, it is a very complex challenge.

On the other hand, the EL1 methodology provided by the Italian Guidelines can be considered as one of the few attempts for a unified methodology for large-scale applications. Nonetheless, the limits of such a methodology are worth discussing. As a matter of fact, the application of the EL1 method needs a deep knowledge based on expert judgement of the considered churches and thus the accuracy of the outputs (i.e., an empirical estimation of the resisting acceleration) may not be proportionate to the assessment efforts needed for the application of the method. Another aspect is that the empirical laws provided in Italian Guidelines for EL1 analyses have been calibrated on a set of data not including the last seismic events, and thus the knowledge acquired in recent decades in this field. In this sense, a continuous effort of revision and updating is envisaged to increase its accuracy. Another critical aspect is represented by the fact that, according to this empirical method, the vulnerability values obtained in recent applications were too often close to the median value. It is reasonable to think, therefore, that a hybrid strategy could be developed in which extensive parametric EL2 and/or EL3 analyses on different macro-elements could be used to calibrate mechanics-based EL1 strategies. This could provide a more reliable 
tool based on a simplified mechanical approach rather than on an empirical one, especially in those cases where observation of real damage due to past earthquakes is not available.

With reference to EL2 methodologies, and in particular kinematic limit analysis, one of the most significant issues in their applications is the definition of block subdivisions when the in-plane behaviour of a structural macro-element is investigated. Whereas in curved structures this could be overcome by an iterative procedure entailing all the possible position of hinges [50], in other cases, such as façades and triumphal arches, this can be more complex since the block subdivisions depend not only on hinge positions but also on both direction and path of subdivision lines. Thus, in this sense the implementation of an automatic tool or software able to solve a wide set of general cases by assuming the hypothesis of the limit analysis is an active direction for research [90]. On the other hand, it must be pointed out that, according to Italian Code, the acceleration returned by a linear limit analysis corresponds to damage mechanism activation (i.e., Damage Limit State-DLS). In general, it should be remarked that, in principle, Heyman's assumptions for masonry behaviour should lead to an underestimation of the effective load capacity, since tensile strength is assumed null. However, unconservative results may also be obtained if the underlying hypotheses regarding negligible sliding and infinite compressive strength are not fulfilled. In this context, enhanced limit analysis formulations accounting for more sophisticated material descriptions are worth mentioning [91,92]. Moreover, since the results achievable with kinematic limit analysis represent an upper bound solution, special care should be taken in ensuring that the mechanism under consideration is effectively the one minimising the corresponding load multiplier.

Nonetheless, EL2 analyses can be hardly extended to all the structural components of masonry churches. In this sense, a combined approach consisting of assessment of the most vulnerable elements by means of EL3 global analyses, and subsequent performance of limit analyses on such elements, can represent a good compromise [93].

As far as EL3 methodologies are concerned, several aspects are worth mentioning. Compared to EL2 assessment strategies, EL3 needs a higher level of knowledge of the structure and entails a significant computational demand. This means that applications to scales larger than the structural one are hardly feasible due to either lack of data or insufficient computational resources. Hybrid strategies for the calibration of EL1 models as the ones envisaged above for EL2 methods [94] could, nonetheless, be potentially developed, and this appears as a promising research direction.

Concerning in depth FE analysis of historical masonry churches, several issues are still open. First, the number of different material models developed over the years and implemented in structural computer codes has raised concerns on the objectivity of the results obtained. As a consequence, the assessment of advanced numerical models has been become a topic of increasing interest in the scientific community $[95,96]$. Acknowledging the different hypotheses at the base of the models, and the selection of material parameters should be considered model-dependent [97], and appropriate tests should be carried out to estimate them. This also brings additional problems. Since invasive testing is not possible in case of buildings of artistic value, non-destructive testing such as dynamic testing is often the only possibility to achieve deeper knowledge on material characterisation [98-100]. In principle this prevents the designer from obtaining parameters other than elastic. Some recent studies tried to capture other aspects, such as degradation of the material, and calibrate nonlinear parameters [101]. To date, however, the selection of post-elastic behaviour for masonry (historical, in particular) is still an open issue that is not standardised in building codes. This is even more relevant since both Italian and European codes implicitly push toward the adoption of the equivalent frame method, which, as discussed above, is not reliable for masonry churches. Hence, also in this case, standardised rules would be of great help for practitioners.

The above critical discussion about the different detail levels of seismic vulnerability assessment of masonry churches addressed in this paper is summarized in Table 7. 


\subsection{Proposal of a Smart Management Policy}

The vulnerability assessment strategies outlined in this review seem to rationally suggest that suitable policies for historical church management should be based on a multilevel methodology, following a qualitative flowchart as shown in Figure 7. A preliminary low-level screening of the wide church heritage is necessary to adopt preventive, rather than reparative, approaches. In this sense, identifying the riskiest dioceses and municipalities by means of EL0 methods is a fundamental step to move from a territorial to a building scale approach. Then, empirical or simplified-mechanical approaches (i.e., EL1 and EL2, respectively) can be followed to define, among homogeneous populations of churches, those requiring urgent retrofitting interventions, whose design must be based on an accurate study based on EL3 assessment.

Table 7. Pros and cons of different detail level of assessment.

\begin{tabular}{|c|c|c|}
\hline Evaluation Level (EL) & Pros & Cons \\
\hline EL0 & $\begin{array}{l}\text { - } \quad \text { Based on few typological parameters. } \\
\text { Does not require accurate in-situ inspections and } \\
\text { expert judgment. }\end{array}$ & $\begin{array}{l}\text { - } \\
\text { Requires an accurate calibration. } \\
\text { buildings only. } \\
\text { - Strongly case-dependent. }\end{array}$ \\
\hline EL1 & $\begin{array}{l}\text { - } \quad \text { Closed-form methodology. } \\
\text { Applicable at the building scale. }\end{array}$ & $\begin{array}{l}\text { - } \quad \begin{array}{l}\text { Gutmoded formulations (Italian } \\
\text { - } \\
\text { Requires accurate in-situ inspections and } \\
\text { expert judgment. }\end{array} \\
\text { Vulnerability values often close to the median value. }\end{array}$ \\
\hline EL2 & $\begin{array}{l}\text { - } \quad \text { Applicable at both single and territorial scales. } \\
\text { Does not require mechanical parameters } \\
\text { of masonry. } \\
\text { - Possibility to design local retrofitting interventions. }\end{array}$ & $\begin{array}{l}\text { - Difficulty to be applied to general geometries. } \\
\text { - Computing demand when applied to all damage } \\
\text { mechanisms of single buildings. } \\
\text { Lack of accuracy in the cases when Heyman's } \\
\text { hypotheses are not fulfilled }\end{array}$ \\
\hline EL3 & $\begin{array}{l}\text { - } \quad \text { Possibility to perform accurate assessment. } \\
\text { Possibility to design both local and local } \\
\text { retrofitting interventions. } \\
\text { Possibility to calibrate the models based on } \\
\text { dynamical characterizations. }\end{array}$ & $\begin{array}{l}\text { - Uncertainties of mechanical parameters. } \\
\text { Difficulty in interpreting out-of-plane } \\
\text { response (FEM). } \\
\text { Computational and modelling costs in case of } \\
\text { sophisticated modelling. }\end{array}$ \\
\hline
\end{tabular}

\section{Territorial scale}

(National, Interdiocesian)

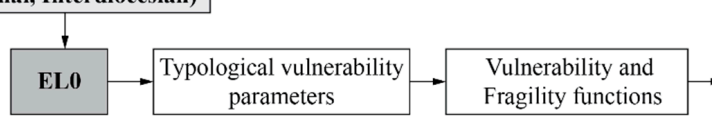

Mean damage grade and

probability of damage level occurrance

Riskiest Dioceses,

Municipalities

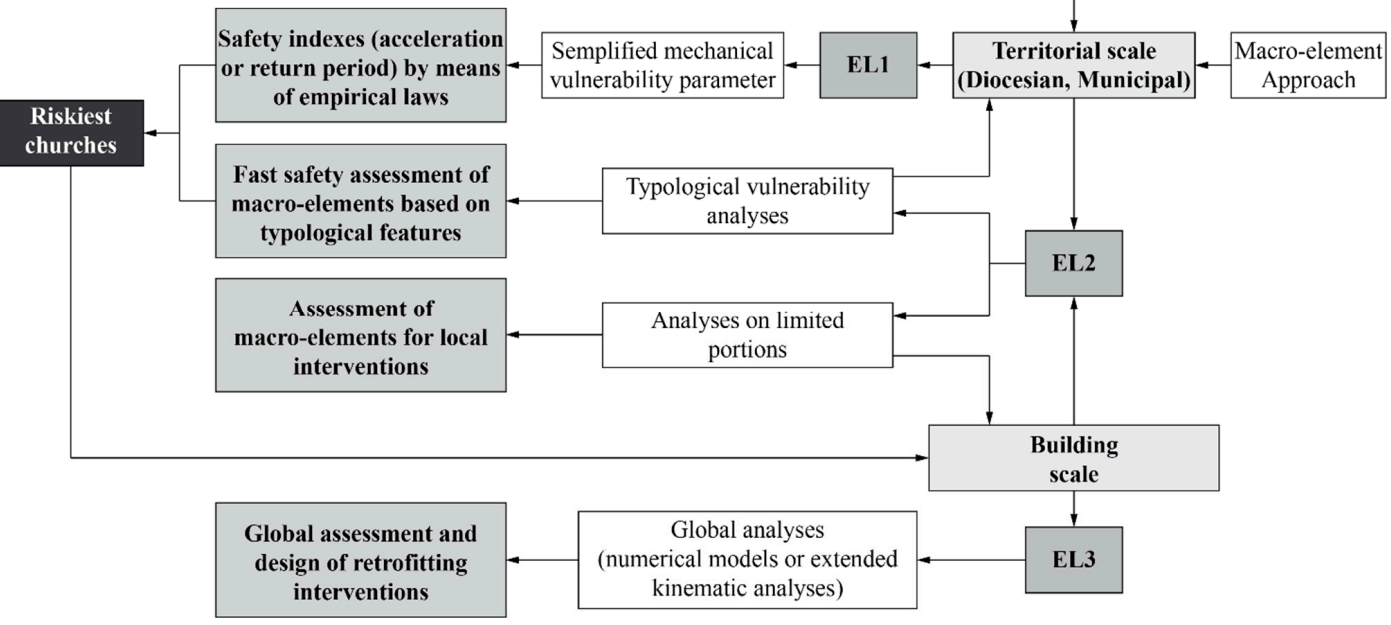

Figure 7. Potential management policy for a smart decision-making process of masonry church assets. 


\section{Conclusions}

In this paper, a wide overview of the methods concerning the seismic assessment of historical masonry churches at different levels of detail has been provided. Of course, each level allows for pursuing specific objectives that range from risk priority scale to design of retrofitting interventions. The study addresses several issues with reference to each detail level of assessment and proposes possible future research directions, generally suggesting a stronger interaction between different methodologies and the definition of hybrid strategies for calibration.

Based on the study and the main outputs, a multilevel procedure for a smart management policy of existing masonry churches has been proposed. Within this, the most simplified assessment procedures EL0 and EL1 are used to rank built assets based on their vulnerability and highlight the need for more accurate investigation and analysis to be performed at EL2 and EL3.

Author Contributions: Conceptualization, J.R. and G.D.M.; methodology, M.Z. and C.C.; investigation, M.Z. and J.R.; data curation, J.R. and M.Z.; writing-original draft preparation, J.R. and M.Z.; writing-review and editing, M.Z., C.C., D.C. and G.D.M.; supervision, C.C. and G.D.M. All authors have read and agreed to the published version of the manuscript.

Funding: Not applicable.

Institutional Review Board Statement: Not applicable.

Data Availability Statement: No new data were created or analyzed in this study. Data sharing is not applicable to this article.

Acknowledgments: This study has been developed within the national project, promoted by the agreement between the Italian consortium ReLUIS and the Department of Civil Protection (DPC), "Seismic Hazard Maps and Damage Scenario (MARS)". C.C. is funded by MUR (Ministry of University and Research) through PON FSE 2014-2020 program (project AIM1879349-2).

Conflicts of Interest: The authors declare no conflict of interest.

\section{References}

1. Despotaki, V.; Silva, V.; Lagomarsino, S.; Pavlova, I.; Torres, J. Evaluation of Seismic Risk on UNESCO Cultural Heritage sites in Europe. Int. J. Archit. Herit. 2018, 12, 1231-1244. [CrossRef]

2. Lagomarsino, S. On the vulnerability assessment of monumental buildings. Bull. Earthq. Eng. 2006, 4, 445-463. [CrossRef]

3. Valente, M.; Milani, G. Seismic response and damage patterns of masonry churches: Seven case studies in Ferrara, Italy. Eng. Struct. 2018, 177, 809-835. [CrossRef]

4. dei Ministri, P.D.C. Valutazione e Riduzione del Rischio Sismico del Patrimonio Culturale con Riferimento alle Norme Tecniche per le Costruzioni di Cui al D.M. 14/01/2008; G.U. No. 47; Ministero per i Beni e le Attività Culturali: Rome, Italy, 2011. (In Italian)

5. Burton, H.V.; Deierlein, G.; Lallemant, D.; Lin, T. Framework for Incorporating Probabilistic Building Performance in the Assessment of Community Seismic Resilience. J. Struct. Eng. 2016, 142, C4015007. [CrossRef]

6. Vona, M.; Mastroberti, M.; Mitidieri, L.; Tataranna, S. New resilience model of communities based on numerical evaluation and observed post seismic reconstruction process. Int. J. Disaster Risk Reduct. 2018, 28, 602-609. [CrossRef]

7. Lagomarsino, S.; Podestà, S. Seismic Vulnerability of Ancient Churches: I. Damage Assessment and Emergency Planning. Earthq. Spectra 2004, 20, S377-S394. [CrossRef]

8. Lagomarsino, S.; Podestà, S. Damage and Vulnerability Assessment of Churches after the 2002 Molise, Italy, Earthquake. Earthq. Spectra 2004, 20, S271-S283. [CrossRef]

9. D'Ayala, D.; Paganoni, S. Assessment and analysis of damage in L'Aquila historic city centre after 6th April 2009. Bull. Earthq. Eng. 2011, 9, 81-104. [CrossRef]

10. Lagomarsino, S. Damage assessment of churches after L'Aquila earthquake. Bull. Earthq. Eng. 2012, 10, 73-92. [CrossRef]

11. Da Porto, F.; Silva, B.; Costa, C.; Modena, C. Macro-scale analysis of damage to churches after earthquake in Abruzzo (Italy) on April 6, 2009. J. Earthq. Eng. 2012, 16, 739-758. [CrossRef]

12. De Matteis, G.; Criber, E.; Brando, G. Damage Probability Matrices for Three- Nave Masonry Churches in Abruzzi After the 2009 L'Aquila Earthquake. Int. J. Archit. Herit. 2016, 10, 120-145.

13. Sorrentino, L.; Liberatore, L.; Decanini, L.D.; Liberatore, D. The performance of churches in the 2012 Emilia earthquakes. Bull. Earthq. Eng. 2014, 12, 2299-2331. [CrossRef]

14. Cescatti, E.; Salzano, P.; Casapulla, C.; Ceroni, F.; Da Porto, F.; Prota, A. Damages to masonry churches after 2016-2017 Central Italy seismic sequence and definition of fragility curves. Bull. Earthq. Eng. 2020, 18, 297-329. [CrossRef] 
15. Hofer, L.; Zampieri, P.; Zanini, M.A.; Faleschini, F.; Pellegrino, C. Seismic damage survey and empirical fragility curves for churches after the August 24, 2016 Central Italy earthquake. Soil Dyn. Earthq. Eng. 2018, 111, 98-109. [CrossRef]

16. Penna, A.; Calderini, C.; Sorrentino, L.; Carocci, C.F.; Cescatti, E.; Sisti, R.; Borri, A.; Modena, C.; Prota, A. Damage to churches in the 2016 central Italy earthquakes. Bull. Earthq. Eng. 2019, 17, 5763-5790. [CrossRef]

17. De Matteis, G.; Zizi, M. Seismic Damage Prediction of Masonry Churches by a PGA-based Approach. Int. J. Archit. Herit. 2019, 13, 1165-1179. [CrossRef]

18. Salzano, P.; Casapulla, C.; Ceroni, F.; Prota, A. Seismic Vulnerability and Simplified Safety Assessments of Masonry Churches in the Ischia Island (Italy) after the 2017 Earthquake. Int. J. Archit. Herit. 2020, 1-27. [CrossRef]

19. Claudia, N.; Cancino, C. Damage assessment of historic earthen sites after the 2007 earthquake in Peru. Adv. Mater. Res. 2010, 133-134, 665-670. [CrossRef]

20. D'Ayala, D.; Benzoni, G. Historic and traditional structures during the 2010 Chile Earthquake: Observations, codes, and conservation strategies. Earthq. Spectra 2012, 28, S425-S451. [CrossRef]

21. Palazzi, N.C.; Favier, P.; Rovero, L.; Sandoval, C.; De La Llera, J.C. Seismic damage and fragility assessment of ancient masonry churches located in central Chile. Bull. Earthq. Eng. 2020, 18, 3433-3457. [CrossRef]

22. Leite, J.; Lourenco, P.B.; Ingham, J.M. Statistical assessment of damage to churches affected by the 2010-2011 Canterbury (New Zealand) earthquake sequence. J. Earthq. Eng. 2013, 17, 73-97. [CrossRef]

23. Marotta, A.; Sorrentino, L.; Liberatore, D.; Ingham, J.M. Vulnerability Assessment of Unreinforced Masonry Churches Following the 2010-2011 Canterbury Earthquake Sequence. J. Earthq. Eng. 2017, 21, 912-934. [CrossRef]

24. Peña, F.; Chávez, M.M. Seismic behavior of Mexican colonial churches. Int. J. Archit. Herit. 2016, 10, 332-345. [CrossRef]

25. Giuffrè, A. Restauro e Sicurezza in Zona Sismica. La Cattedrale di S. Angelo dei Lombardi; Nuova serie 1; Palladio: Rome, Italy, 1998; pp. 95-120. (In Italian)

26. Grünthal, G.; Musson, R.M.W.; Schwarz, J.; Stucchi, M. (Eds.) European Macroseismic Scale 1998. (EMS-98). In Cahiers du Centre Européen de Géodynamique et de Séismologie; Centre Européen de Géodynamique et de Séismologie: Luxembourg, 1998; volume 15, p. 99. [CrossRef]

27. D'Amato, M.; Laterza, M.; Diaz Fuentes, D. Simplified Seismic Analyses of Ancient Churches in Matera's Landscape. Int. J. Archit. Herit. 2020, 14, 119-138. [CrossRef]

28. Braga, F.; Dolce, M.; Liberatore, D. A Statistical Study on Damaged Buildings and an Ensuing Review of the MSK-76 Scale. In Proceedings of the Seventh European Conference on Earthquake Engineering, Athens, Greece, 20-25 September 1982; pp. 431-450.

29. Lagomarsino, S.; Podestà, S. Seismic Vulnerability of Ancient Churches: II. Statistical Analysis of Surveyed Data and Methods for Risk Analysis. Earthq. Spectra 2004, 20, S395-S412. [CrossRef]

30. Bernardini, A.; Lagomarsino, S. The seismic vulnerability of architectural heritage. Proc. Inst. Civ. Eng. Struct. Build. 2008, 161, 171-181. [CrossRef]

31. Canuti, C.; Carbonari, S.; Dall'Asta, A.; Dezi, L.; Gara, F.; Leoni, G.; Morici, M.; Petrucci, E.; Prota, A.; Zona, A. Post-Earthquake Damage and Vulnerability Assessment of Churches in the Marche Region Struck by the 2016 Central Italy Seismic Sequence. Int. J. Archit. Herit. 2021, 15, 1000-1021. [CrossRef]

32. De Matteis, G.; Brando, G.; Corlito, V. Predictive model for seismic vulnerability assessment of churches based on the 2009 L'Aquila earthquake. Bull. Earthq. Eng. 2019, 17, 4909-4936. [CrossRef]

33. Lagomarsino, S.; Giovinazzi, S. Macroseismic and mechanical models for the vulnerability and damage assessment of current buildings. Bull. Earthq. Eng. 2006, 4, 415-443. [CrossRef]

34. Sandi, H.; Floricel, I. Analysis of seismic risk affecting the existing building stock. In Proceedings of the 10th European Conference on Earthquake Engineering, Vienna, Austria, 28 August-2 September 1994; A.A. Balkema: Rotterdam, The Netherlands, 1994; Volume 2, pp. 1105-1110.

35. Brandonisio, G.; Lucibello, G.; Mele, E.; De Luca, A. Damage and performance evaluation of masonry churches in the 2009 L'Aquila earthquake. Eng. Fail. Anal. 2013, 34, 693-714. [CrossRef]

36. Lagomarsino, S.; Cattari, S.; Ottonelli, D.; Giovinazzi, S. Earthquake damage assessment of masonry churches: Proposal for rapid and detailed forms and derivation of empirical vulnerability curves. Bull. Earthq. Eng. 2019, 17, 3327-3364. [CrossRef]

37. Faenza, L.; Michelini, A. Regression analysis of MCS intensity and ground motion parameters in Italy and its application in ShakeMap. Geophys. J. Int. 2010, 180, 1138-1152. [CrossRef]

38. Masi, A.; Lagomarsino, S.; Dolce, M.; Manfredi, V.; Ottonelli, D. Towards the updated Italian seismic risk assessment: Exposure and vulnerability modelling. Bull. Earthq. Eng. 2021, 19, 3253-3286. [CrossRef]

39. Mouroux, P.; Le Brun, B. Presentation of RISK-UE Project. Bull. Earthq. Eng. 2006, 4, 323-339. [CrossRef]

40. Goded, T.; Lewis, A.; Stirling, M. Seismic vulnerability scenarios of Unreinforced Masonry churches in New Zeland. Bull. Earthq. Eng. 2018, 16, 3957-3999. [CrossRef]

41. National Group for Earthquakes Defense (GNDT). First and Second Level Form for Exposure, Vulnerability and Damage Survey (Masonry and Reinforced Concrete); GNDT: Rome, Italy, 1994.

42. Lourenço, P.B.; Roque, J.A. Simplified indexes for the seismic vulnerability of ancient masonry buildings. Constr. Build. Mater. 2006, 20, 200-208. [CrossRef]

43. Palazzi, N.C.; Rovero, L.; De La Llera, J.C.; Sandoval, C. Preliminary assessment on seismic vulnerability of masonry churches in central Chile. Int. J. Archit. Herit. 2019, 14, 829-848. [CrossRef] 
44. Heyman, J. The Masonry Arch; Ellis Horwood Ltd.: Chichester, UK, 1982.

45. De La Hire, P. Sur la construction des voûtes dans les édifices. In Mémoires de l'Académie Royale des Sciences de Paris; Académie Royale des Sciences: Paris, France, 1712. (In French)

46. Mèry, E. Sur l'equilibre des voutes en berceu. In Annales de Ponts et Chaussess; PYC Édition: Paris, France, 1840. (In French)

47. Criber, E.; Brando, G.; De Matteis, G. The effects of L'Aquila earthquake on the St. Gemma church in Goriano Sicoli: Part I: Damage survey and kinematic analysis. Bull. Earthq. Eng. 2015, 13, 3713-3732. [CrossRef]

48. Cavalagli, N.; Gusella, V.; Severini, L. Lateral loads carrying capacity and minimum thickness of circular and pointed masonry arches. Int. J. Mech. Sci. 2016, 115-116, 645-656. [CrossRef]

49. Brandonisio, G.; Mele, E.; De Luca, A. Limit analysis of masonry circular buttressed arches under horizontal loads. Meccanica 2017, 52, 2547-2565. [CrossRef]

50. Zizi, M.; Cacace, D.; Rouhi, J.; Lourenço, P.B.; De Matteis, G. Automatic procedures for the safety assessment of stand-alone masonry arches. Int. J. Archit. Herit. 2021, 1-19. [CrossRef]

51. Lourenço, P.B. Computational Strategies for Masonry Structures. Ph.D. Thesis, University of Porto, Porto, Portugal, 1996.

52. Roca, P.; Molins, C.; Mari, A.R. Strength capacity of masonry wall structures by the equivalent frame method. J. Struct. Eng. 2005 131, 1601-1610. [CrossRef]

53. Lagomarsino, S.; Penna, A.; Galasco, A.; Cattari, S. TREMURI program: An equivalent frame model for the nonlinear seismic analysis of masonry buildings. Eng. Struct. 2013, 56, 1787-1799. [CrossRef]

54. Dejong, M.J.; Beletti, B.; Hendriks, M.A.N.; Rots, J.G. Shell elements for sequentially linear analysis: Lateral failure of masonry structures. Eng. Struct. 2009, 31, 1382-1392. [CrossRef]

55. Noor-E-Khuda, S.; Dhanasekar, M.; Thambiratnam, D.P. An explicit finite element modelling method for masonry walls under out-of-plane loading. Eng. Struct. 2016, 113, 103-120. [CrossRef]

56. Casolo, S.; Milani, G. Semplified out-of-plane modelling of three-leaf masonry walls accounting for the material texture. Constr. Build. Mater. 2013, 40, 330-351. [CrossRef]

57. Betti, M.; Galano, L.; Vignoli, A. Finite Element Modelling for Seismic Assessment of Historic Masonry Buildings. In Earthquakes and Their Impact on Society; D'Amico, S., Ed.; Springer: Cham, Switzerland, 2013; pp. 377-415.

58. Borst, R.; Remmers, J.; Needleman, A.; Abellan, M.A. Discrete vs smeared crack models for concrete fracture: Bridging the gap. Int. J. Numer. Anal. Methods Geomech. 2004, 28, 583-607. [CrossRef]

59. Alfarah, B.; López-Almansa, F.; Oller, S. New methodology for calculating damage variables evolution in Plastic Damage Model for RC structures. Eng. Struct. 2017, 132, 70-86. [CrossRef]

60. Betti, M.; Vignoli, A. Numerical assessment of the static and seismic behaviour of the basilica of Santa Maria all'Impruneta (Italy). Constr. Build. Mater. 2011, 25, 4308-4324. [CrossRef]

61. Formisano, A.; Vaiano, G.; Fabbrocino, F.; Milani, G. Seismic vulnerability of Italian masonry churches: The case of the Nativity of Blessed Virgin Mary in Stellata of Bondeno. J. Build. Eng. 2018, 20, 179-200. [CrossRef]

62. Grazzini, A.; Chiarabrando, F.; Foti, S.; Sammartano, G.; Spanò, A. Multidisciplinary Study on the Seismic Vulnerability of St. Agostino Church in Amatrice following the 2016 Seismic Sequence. Int. J. Archit. Herit. 2020, 14, 885-902. [CrossRef]

63. De Matteis, G.; Mazzolani, F.M. The Fossanova Church: Seismic Vulnerability Assessment by Numeric and Physical Testing. Int. J. Archit. Herit. 2010, 4, 222-245. [CrossRef]

64. Kujawa, M.; Lubowiecka, I.; Szymczak, C. Finite element modelling of a historic church structure in the context of a masonry damage analysis. Eng. Fail. Anal. 2020, 107, 104233. [CrossRef]

65. Karanikoloudis, G.; Lourenço, P.B. Structural assessment and seismic vulnerability of earthen historic structures. Application of sophisticated numerical and simple analytical models. Eng. Struct. 2018, 160, 488-509. [CrossRef]

66. Alforno, M.; Monaco, A.; Venuti, F.; Calderini, C. Validation of simplified micro-models for the static analysis of masonry arches and vaults. Int. J. Archit. Her. 2021, 15, 1196-1212. [CrossRef]

67. Gaetani, A.; Bianchini, N.; Lourenço, P.B. Simplified micro-modelling of masonry cross vaults: Stereotomy and interface issues. Int. J. Mason. Res. Innov. 2021, 6, 97-125. [CrossRef]

68. Milani, G.; Valente, M. Comparative pushover and limit analyses on seven masonry churches damaged by the 2012 EmiliaRomagna (Italy) seismic events: Possibilities of non-linear finite elements compared with pre-assigned failure mechanisms. Eng. Fail. Anal. 2015, 47, 129-161. [CrossRef]

69. Betti, M.; Vignoli, A. Modelling analysis of a Romanesque church under earthquake loading: Assessment of seismic resistance. Eng. Struct. 2008, 30, 352-367. [CrossRef]

70. Addessi, D.; Marfia, S.; Sacco, E. A plastic nonlocal damage model. Comput. Methods Appl. Mech. Eng. 2002, 19, 1291-1310. [CrossRef]

71. Trovalusci, P.; Masiani, R. Non-linear micropolar and classical continua for anisotropic discontinuous materials. Int. J. Solids Struct. 2003, 40, 1281-1297. [CrossRef]

72. Petracca, M.; Pelà, L.; Rossi, R.; Oller, S.; Camata, G.; Spacone, E. Regularization of first order computational homogeni-zation for multiscale analysis of masonry structures. Comput. Mech. 2016, 57, 257-276. [CrossRef]

73. Cundall, P.A.; Strack, O.D.L. A discrete numerical model for granular assemblies. Géotechnique 1979, 29, 47-65. [CrossRef]

74. Pulatsu, B.; Ercdogmus, E.; Lourenço, P.B.; Lemos, V.; Tuncay, K. Simulation of the in-plane structural behavior of unreinforced masonry walls and buildings using DEM. Structures 2020, 27, 2274-2287. [CrossRef] 
75. Foti, D.; Vacca, V.; Facchini, I. DEM modeling and experimental analysis of the static behavior of a dry-joints masonry cross vaults. Constr. Build. Mater. 2018, 170, 111-120. [CrossRef]

76. Mclnerney, J.; Dejong, M.J. Discrete Element Modeling of Groin Vault Displacement Capacity. Int. J. Archit. Her. 2015, 9, 1037-1049. [CrossRef]

77. Lemos, J.V. Discrete Element Modeling of the Seismic Behavior of Masonry Construction. Buildings 2019, 9, 43. [CrossRef]

78. Gonen, S.; Pulatsu, B.; Erdogmus, E.; Karaesmen, E.; Karaesmen, E. Quasi-Static Nonlinear Seismic Assessment of a Fourth Century, A.D. Roman Aqueduct in Istanbul, Turkey. Heritage 2021, 4, 401-421. [CrossRef]

79. Ferrante, A.; Loverdos, D.; Clementi, F.; Milani, G.; Formisano, A.; Lenci, S.; Sarhosis, V. Discontinuous approaches for nonlinear dynamic analyses of an ancient masonry tower. Eng. Struct. 2021, 230, 111626. [CrossRef]

80. Pantò, B.; Cannizzaro, F.; Caddemi, S.; Caliò, I. 3D macro-element modelling approach for seismic assessment of historical masonry churches. Adv. Eng. Softw. 2016, 97, 40-59. [CrossRef]

81. Zizi, M.; Corlito, V.; Lourenço, P.B.; De Matteis, G. Seismic vulnerability of masonry churches in Abruzzi region, Italy. Structures 2021, 32, 662-680. [CrossRef]

82. Yacila, J.; Camata, G.; Salsavilca, J.; Tarque, N. Pushover analysis of confined masonry walls using a 3D macro-modelling approach. Eng. Struct. 2019, 201, 109731. [CrossRef]

83. Jain, A.; Acito, M.; Chesi, C. Seismic sequence of 2016-17: Linear and non-linear interpretation models for evolution of damage in San Francesco church, Amatrice. Eng. Struct. 2020, 211, 110418. [CrossRef]

84. Papa, G.S.; Tateo, V.; Parisi, M.A.; Casolo, S. Seismic response of a masonry church in Central Italy: The role of interventions on the roof. Bull. Earthq. Eng. 2021, 19, 1151-1179. [CrossRef]

85. Milani, G.; Shehu, R.; Valente, M. A kinematic limit analysis approach for seismic retrofitting of masonry towers through steel tie-rods. Eng. Struct. 2018, 160, 212-228. [CrossRef]

86. Chisari, C.; Cacace, D.; De Matteis, G. Parametric Investigation on the Effectiveness of FRM-Retrofitting in Masonry Buttressed Arches. Buildings 2021, 11, 406. [CrossRef]

87. Lourenço, P.B.; Ciocci, M.P.; Greco, F.; Karanikoloudis, G.; Cancino, C.; Torrealva, D.; Wong, K. Traditional techniques for the rehabilitation and protection of historic earthen structures: The seismic retrofitting project. Int. J. Archit. Her. 2019, 13, 15-32. [CrossRef]

88. Milani, G.; Shehu, R.; Valente, M. Possibilities and limitations of innovative retrofitting for masonry churches: Advanced computations on three case studies. Constr. Build. Mater. 2017, 147, 239-263. [CrossRef]

89. Angjeliu, G.; Coronelli, D.; Cardani, G.; Boothby, T. Structural assessment of iron tie rods based on numerical modelling and experimental observations in Milan Cathedral. Eng. Struct. 2020, 206, 109690. [CrossRef]

90. Chiozzi., A.; Grillanda, N.; Milani, G.; Tralli, A. UB-ALMANAC: An adaptive limit analysis NURBS-based program for the automatic assessment of partial failure mechanisms in masonry churches. Eng. Fail. Anal. 2018, 85, 201-220. [CrossRef]

91. Portioli, F.; Casapulla, C.; Gilbert, M.; Cascini, L. Limit analysis of 3D masonry block structures with non-associative frictional joints using cone programming. Comput. Struct. 2014, 143, 108-121. [CrossRef]

92. Li, H.X.; Yu, H.S. Kinematic limit analysis of frictional materials using nonlinear programming. Int. J. Solids Struct. 2005, 42, 4058-4076. [CrossRef]

93. Funari, M.F.; Spadea, S.; Lonetti, P.; Fabbrocino, F.; Luciano, R. Visual programming for structural assessment of out-of-plane mechanisms in historic masonry structures. J. Build. Eng. 2020, 31, 101425. [CrossRef]

94. Shakya, M.; Varum, H.; Vicente, R.; Costa, A. Seismic vulnerability assessment methodology for slender masonry structures. Int. J. Archit. Herit. 2018, 12, 1297-1326. [CrossRef]

95. Cattari, S.; Magenes, G. Benchmarking the software packages to model and assess the seismic response of unreinforced masonry existing buildings through nonlinear static analyses. Bull. Earthq. Eng. 2021. [CrossRef]

96. Zizi, M.; Chisari, C.; Rouhi, J.; De Matteis, G. Comparative analysis on macroscale material models for the prediction of masonry in-plane behavior. Bull. Earth. Eng. 2021, 1-34. [CrossRef]

97. Chisari, C.; Macorini, L.; Amadio, C.; Izzuddin, B.A. Identification of mesoscale model parameters for brick-masonry. Int. J. Solids Struct. 2018, 146, 224-240. [CrossRef]

98. Gentile, C.; Saisi, A.; Cabboi, A. Structural identification of a masonry tower based on operational modal analysis. Int. J. Archit. Herit. 2015, 9, 98-110. [CrossRef]

99. Ramos, L.F.; Marques, L.; Lourenço, P.B.; De Roeck, G.; Campos-Costa, A.; Roque, J. Monitoring historical masonry structures with operational modal analysis: Two case studies. Mech. Syst. Signal Process. 2010, 24, 1291-1305. [CrossRef]

100. Aloisio, A.; Di Pasquale, A.; Alaggio, R.; Fragiacomo, M. Assessment of Seismic Retrofitting Interventions of a Masonry Palace Using Operational Modal Analysis. Int. J. Archit. Herit. 2020, 1-13. [CrossRef]

101. Pellegrini, D.; Girardi, M.; Lourenço, P.B.; Masciotta, M.G.; Mendes, N.; Padovani, C.; Ramos, L.F. Modal analysis of historical masonry structures: Linear perturbation and software benchmarking. Constr. Build. Mater. 2018, 189, 1232-1250. [CrossRef] 